\title{
The oldest specialized tetrapod herbivore: A new eupelycosaur from the Permian of New Mexico, USA
}

\author{
Spencer G. Lucas, Larry F. Rinehart, and Matthew D. Celeskey
}

\begin{abstract}
Gordodon kraineri is a new genus and species of edaphosaurid eupelycosaur known from an associated skull, lower jaw and incomplete postcranium found in the early Permian Bursum Formation of Otero County, New Mexico, USA. It has a specialized dental apparatus consisting of large, chisel-like incisors in the front of the jaws separated by a long diastema from relatively short rows of peg-like maxillary and dentary cheek teeth. The dorsal vertebrae of Gordodon have long neural spines that bear numerous, randomly arranged, small, thorn-like tubercles. The tubercles on long neural spines place Gordodon in the Edaphosauridae, and the dental apparatus and distinctive tubercles on the neural spines distinguish it from the other edaphosaurid genera-Edaphosaurus, Glaucosaurus, Lupeosaurus and lanthasaurus. Gordodon is the oldest known tetrapod herbivore with a dentary diastema, extending the temporal range of that anatomical feature back 95 million years from the Late Triassic. The dental apparatus of Gordodon indicates significantly different modes of ingestion and intraoral transport of vegetable matter than took place in Edaphosaurus and thus represents a marked increase in disparity among edaphosaurids. There were two very early pathways to tetrapod herbivory in edaphosaurid evolution, one toward generalized browsing on high-fiber plant items (Edaphosaurus) and the other (Gordodon) toward more specialized browsing, at least some of it likely on higher nutrient, low fiber plant items. Gordodon shows a surprisingly early specialization of the dental apparatus and indicates how incomplete our knowledge is of edaphosaurid evolution, disparity and diversity.
\end{abstract}

Spencer G. Lucas. New Mexico Museum of Natural History, 1801 Mountain Road N. W., Albuquerque, 87104 New Mexico, USA. spencer.lucas@state.nm.us

Larry F. Rinehart. New Mexico Museum of Natural History, 1801 Mountain Road N. W., Albuquerque,

http://zoobank.org/BA32DBE6-21CD-4CA3-A663-CB750B1A723F

Lucas, Spencer G., Rinehart, Larry F., and Celeskey, Matthew D. 2018. The oldest specialized tetrapod herbivore: A new eupelycosaur from the Permian of New Mexico, USA. Palaeontologia Electronica 21.3.39A 1-42. https://doi.org/10.26879/899 palaeo-electronica.org/content/2018/2343-new-eupelycosaur

Copyright: November 2018 Paleontological Society.

This is an open access article distributed under the terms of Attribution-NonCommercial-ShareAlike 4.0 International (CC BY-NC-SA 4.0), which permits users to copy and redistribute the material in any medium or format, provided it is not used for commercial purposes and the original author and source are credited, with indications if any changes are made.

creativecommons.org/licenses/by-nc-sa/4.0/ 
87104 New Mexico, USA. larry.rinehart@earthlink.net

Matthew D. Celeskey. New Mexico Museum of Natural History, 1801 Mountain Road N. W., Albuquerque, 87104 New Mexico, USA. matt.celeskey@hmnh.org

Keywords: New Mexico; Permian; eupelycosaur; edaphosaur; high-fiber herbivory; new genus; new species

Submission: 15 June 2018 Acceptance: 26 October 2018

\section{INTRODUCTION}

The oldest tetrapod fossils are footprints of Middle Devonian age, and, in Upper Carboniferous (Pennsylvanian) strata, the first fossils of amniotes are known. Prior to the Late Pennsylvanian, tetrapod fossils indicate no direct consumption of highfiber plant foods by tetrapods. Then, during the Late Pennsylvanian, the first obligate high-fiber herbivores appear in the tetrapod fossil record, the diadectomorphs, bolosaurids, caseasaurs and edaphosaurid eupelycosaurs (e.g., Hotton et al., 1997; Sues and Resiz, 1998; Reisz and Sues, 2000; Reisz and Fröbisch, 2014; Modesto et al., 2015; Spindler et al., 2016). Identification of herbivory in these tetrapods is based primarily on their dentition and skull structures, which indicate, to varying degrees, the ability to crop and masticate vegetation.

Of these early tetrapod herbivores, edaphosaurid eupelycosaurs have the widest distribution. Edaphosaurid fossils are known from the western and eastern USA, and there are a few records in Europe (Romer and Price, 1940; Reisz, 1986; Berman et al., 1997; Voigt et al., 2014). Although they have a long stratigraphic (temporal) range through part of the Late Pennsylvanian and much of the early Permian ( 23 million years), known edaphosaurid taxonomic diversity is low. Thus, only four genera (three monospecific, one known from a single specimen) are known: Edaphosaurus Cope, Glaucosaurus Williston, Lupeosaurus Romer and lanthasaurus Reisz and Berman. Edaphosaurus has Late Pennsylvanian and early Permian records, lanthasaurus is known from the Late Pennsylvanian, and Lupeosaurus and Glaucosaurus have very limited early Permian records.

In New Mexico, USA, edaphosaurid fossils have long been known from nonmarine red beds of Late Pennsylvanian and early Permian age. All of these fossils are referred to Edaphosaurus, and, when identified to the species level, to E. novomexicanus Williston and Case, a Late Pennsylvanian and early Permian species originally described from the state (e.g., Williston and Case, 1913; Vaughn, 1963, 1969b; Modesto and Reisz, 1992; Lucas et al., 1999, 2005, 2014; Harris et al., 2004; Berman et al., 2015). Most of these New Mexican edaphosaur records are of isolated neural spines with the relatively thick and blunt-tipped tubercles characteristic of Edaphosaurus.

We document here a new edaphosaurid genus and species from New Mexico with surprising specializations for herbivory. This taxon is based on an exceptionally well-preserved skull, lower jaw and incomplete postcranial skeleton collected from lowermost Permian strata of the Bursum Formation in southern New Mexico (Figure 1). We establish this new taxon by describing this specimen and comparing it to and contrasting it with known edaphosaurids. We also present a hypothesis of the phylogenetic relationships of the new taxon and, at greater length, explore its functional morphology as a surprisingly specialized early tetrapod herbivore. We summarize with a time-calibrated phylogeny of edaphosaurids with which to understand the timing of the acquisition of herbivory in this family of eupelycosaurs.

\section{MATERIALS AND METHODS}

The fossil described here is a skull, lower jaw and incomplete postcranial skeleton that is part of the collection of the New Mexico Museum of Natural History and Science, Albuquerque, New Mexico. It was collected by Museum staff in 20132014, permitted and assisted by the Road Department of Otero County, New Mexico, under the supervision of Wade Moore, Road Department Superintendent.

Morphological variation among edaphosaurid eupelycosaurs was studied by examination of edaphosaurid fossils in the collection of the Field Museum of Natural History, Chicago and based on the published literature cited below. The stratigraphic nomenclature and age assignment of the fossil are those of Krainer et al. (2003), Krainer and Lucas (2013) and Lucas (2013b). 


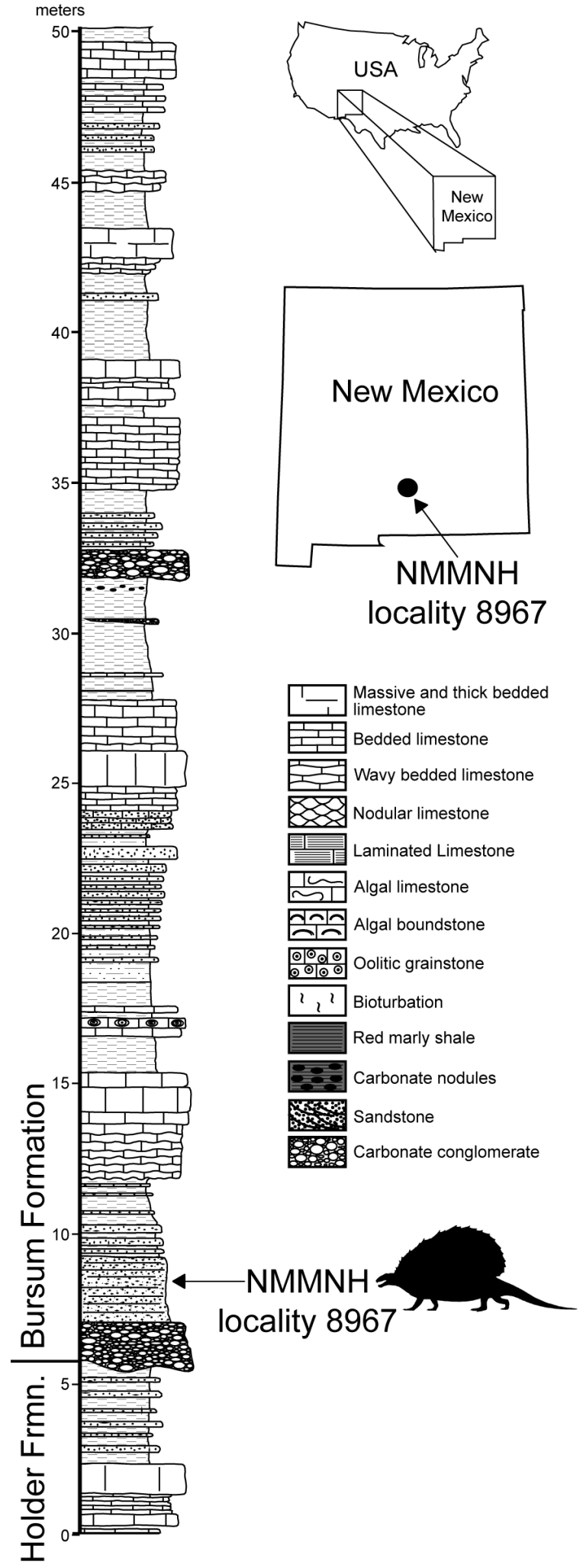

FIGURE 1. Generalized location map of the type locality of Gordodon kraineri in southern New Mexico, and measured stratigraphic section (after Krainer et al., 2003) showing the stratigraphic horizon of the type locality in the lower part of the Bursum Formation.
Measurements were made with needle-point calipers and metric rulers. Metric data were analyzed using Microsoft Excel 2007 and JMP Version 10 (2012, SAS Institute Inc., Cary, North Carolina, USA). Photographs were taken with SLR digital cameras. Cladistic analysis was undertaken using Mesquite 3.2 (Maddison and Maddison, 2017) and Phylogenetic Analysis Using Parsimony (PAUP)* 4.0a (build 158) (Swofford, 2002).

\section{Institutional Abbreviations}

$\mathrm{AMNH}=$ American Museum of Natural History, New York; NMMNH = New Mexico Museum of Natural History and Science, Albuquerque; ROM = Royal Ontario Museum, Toronto.

\section{GEOLOGICAL SETTING}

The holotype specimen of the new edaphosaurid was discovered by Ethan Schuth in March 2013 while on a fieldtrip for a geology class of the University of Oklahoma. The fossil was exposed in a roadcut of a county road near Alamogordo in Otero County, New Mexico (Figure 1). Schuth and Dr. Lynn Soreghan contacted one of us (SGL), and collection of the fossil took place in 2013-2014. The fossil site is locality 8967 in the NMMNH database, and additional information on the locality is available to qualified researchers.

The fossil was found stratigraphically low in the Bursum Formation, about $3 \mathrm{~m}$ above its base (Figure 1). The fossil-bearing stratum is a tabularbedded, medium- to coarse-grained, micaceous litharenitic sandstone that is light olive gray $(5 Y 6 / 1)$ to grayish olive (10Y4/2) in color. This sandstone bed is the upper part of a channel-fill complex of conglomerate and sandstone at the base of the Bursum Formation that is locally scoured into the top of the underlying Holder Formation (Krainer et al., 2003). The Bursum Formation is a stratigraphic unit of mixed marine and nonmarine origin (Krainer and Lucas, 2013). The lowermost beds of the Bursum Formation at the edaphosaur locality are a characteristic fluvial lithofacies (Krainer et al., 2003; Krainer and Lucas, 2013).

Calcareous microfossils (mostly foraminiferans, including fusulinids) indicate that the Holder Formation is Virgilian in age, and the Bursum Formation is early Wolfcampian in age (e.g., Thompson, 1942; Otte, 1959; Pray, 1961; Steiner and Williams, 1968; Krainer et al., 2003). The stratigraphically lowest early Wolfcampian fusulinids are 25-30 $\mathrm{m}$ above the base of the Bursum Formation (Otte, 1959; Steiner and Williams, 1968), which is stratigraphically above the edaphosaur 
locality. The stratigraphically highest foraminiferans of Virgilian age are in the upper Holder Formation, about $5 \mathrm{~m}$ below the base of the Bursum Formation. Thus, strictly speaking, the edaphosaur locality could be latest Virgilian or earliest Wolfcampian. Conventionally, in the northern Sacramento Mountains of Otero County, the base of the Wolfcampian is drawn at the base of the Bursum Formation (e.g., Otte, 1959; Pray, 1961), and we follow that convention here. We also follow Lucas (2013b) and place the Pennsylvanian-Permian boundary at its traditional position corresponding to the Virgilian-Wolfcampian boundary. Therefore, the new edaphosaurid fossil is of early Permian age. However, if the conodont-based definition of the base of the Permian is used (Davydov et al., 1998), the early Wolfcampian is latest Pennsylvanian, so the new edaphosaurid fossil would be of latest Pennsylvanian age.

\section{SYSTEMATIC PALEONTOLOGY}

\author{
SYNAPSIDA Osborn, 1903 \\ EUPELYCOSAURIA Kemp, 1982 \\ EDAPHOSAURIDAE Cope, 1882 \\ Gordodon gen. nov.
}

zoobank.org/B1F6D232-47D0-47F1-B9FE-717792A51A6E

Type and only known species. Gordodon kraineri sp. nov.

Etymology. Gordo, Spanish for "fat," and Greek odon, "tooth," in reference to the large ("fat") teeth at the anterior end of the snout of the holotype. Gordo also is a reference to the city of Alamogordo, near the type locality.

Diagnosis. Gordodon is a medium-sized edaphosaur (presacral length $\sim 1 \mathrm{~m}$ ) distinguished from the other edaphosaurid genera by: an unique dental apparatus consisting of large chisel-like incisors in the premaxilla and dentary (dentary incisors inferred from empty alveolus) separated by a long diastema from a relatively short row of peg-like maxillary and dentary cheek teeth and tooth plates with small $(<1 \mathrm{~mm})$ teeth on the interior surface of the mandible; preorbital skull length subequal to postorbital skull length; a relatively short nasalmaxilla suture; cervical and anterior dorsal vertebrae with relatively gracile centra that are doublekeeled ventrally; and cervical and dorsal vertebrae have long neural spines that bear up to 12 small, thorn-like lateral tubercles randomly distributed on each side.

Gordodon kraineri sp. nov. zoobank.org/78EF19C9-5BBA-43B6-B6CE-991137105BF7
Etymology. To honor Karl Krainer for his many contributions to our knowledge of the late Paleozoic geology and paleontology of New Mexico.

Holotype. NMMNH P-70796, incomplete skeleton consisting of the skull, lower jaws, all or parts of 21 vertebrae (five cervical vertebrae, four complete dorsal vertebrae, the neural spines in varying states of completeness of 12 additional dorsal vertebrae), parts of five cervical and five dorsal rib pairs, parts of the right and left clavicles and scapulae and parts of two digits of the manus(?) (Figure 2).

Holotype locality. NMMNH locality 8967 , Otero County, New Mexico, USA (Figure 1).

Stratigraphic horizon and age. Lower part of Bursum Formation, early Wolfcampian (early Permian).

\section{Description}

Skull. The skull of Gordodon (Figures 3-5) is essentially complete but only exposed along its right side. It has been compressed medio-laterally, so that some of the dorsal and ventral features of the skull are also visible. A saw cut through the rock during its extraction inadvertently severed the skull along a dorso-ventral line about mid-orbit, removing a strip of the skull about $6.25 \mathrm{~mm}$ wide.

Although the skull of Gordodon is small relative to body size, it is relatively large for an edaphosaurid. At $159 \mathrm{~mm}$ long from the tip of the snout to the tip of the occiput, it is about the length of six dorsal vertebrae. It is low vaulted, relatively dolicocephalic and has nearly equal pre-orbital and post-orbital portions (both are about $65 \mathrm{~mm}$ long). The anterior tip of the snout is formed by the crescent-shaped premaxilla, which bears a single, large, trenchant tooth near its anterior edge. The premaxilla has an arcuate, gently rounded anterior edge, and its external surface is slightly convex.

The narial opening is small, oval and is formed anteriorly by an embayment of the posterior edge of the premaxilla. The embayment continues posterodorsally to the anterior edge of the nasal, which has a long, irregular suture to the posterodorsal edge of the premaxilla. The nasal forms most of the dorsal aspect of the snout. Most of the lateral edge of the nasal is a long suture with the lacrimal, and there is a much shorter nasal-maxilla suture anterior to that. A suture to the prefrontal laterally and the frontal medially forms the posterodorsal edge of the nasal. The nasal also is wrapped around a small septomaxilla anteriorly. The septomaxilla forms the posterior and ventral edges of the narial opening. 

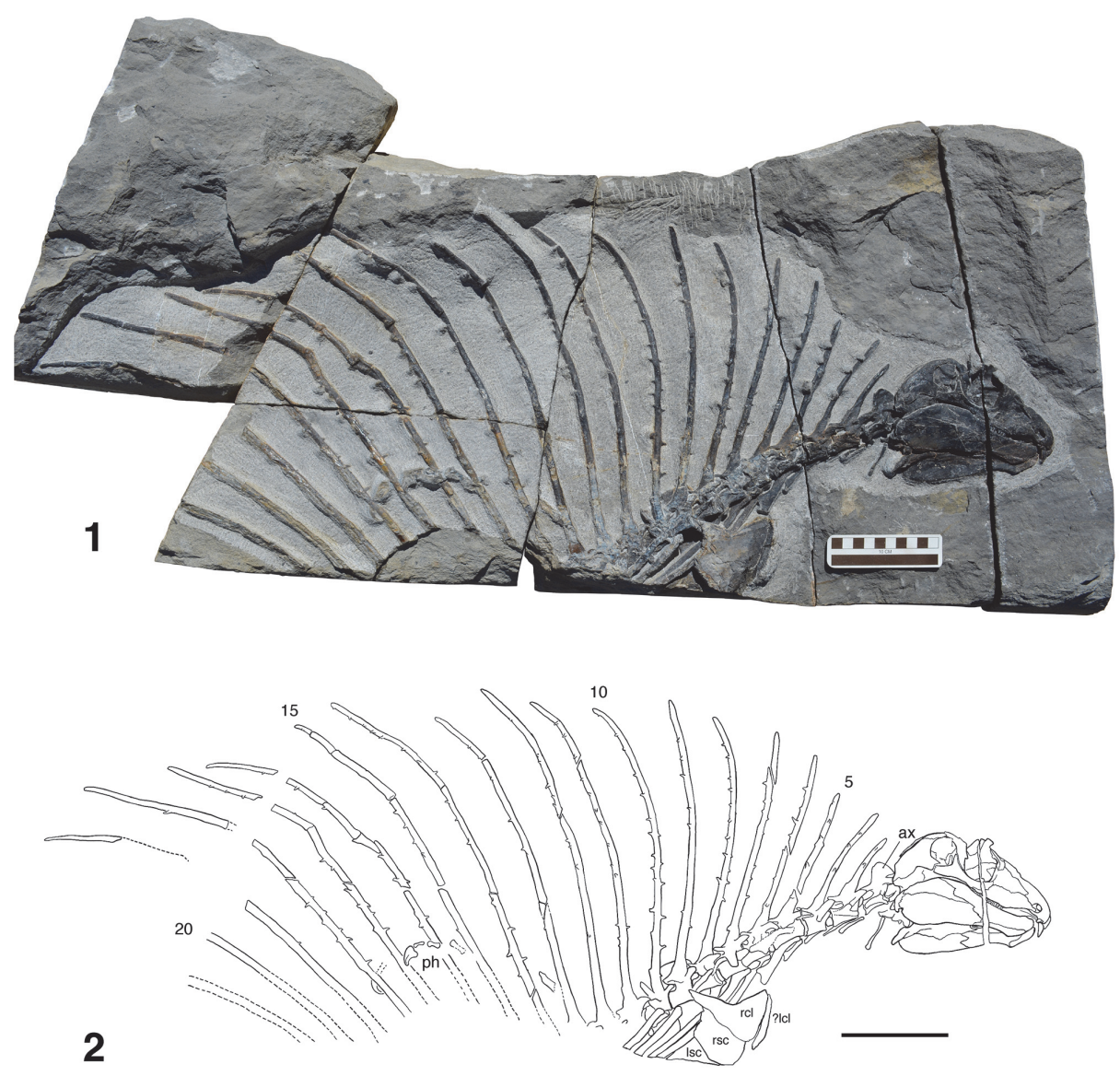

FIGURE 2. Holotype skull, lower jaw and incomplete postcranium of Gordodon kraineri, NMMNH P-70796, photograph (1) and bone map (2). For anatomical abbreviations see the caption to Figure 7 . Scale equals $10 \mathrm{~cm}$.

The lacrimal occupies much of the lateral aspect of the snout. It has a long suture antero-dorsal to the nasal and is sutured to the prefrontal postero-dorsally. Its suture to the maxilla ventrally is a long and irregular line. There is a short, nearly vertical suture of the lacrimal with the anterior edge of the jugal at the antero-ventral margin of the orbit. The posterior border of the lacrimal forms much of the anterior wall of the orbit.

The maxilla is an antero-posteriorly long bone exposed along most of the ventral edge of the snout. It has a posterior process that extends ventral to the jugal to a point postero-ventral to the midpoint of the orbit. Thus, the jugal separates the maxilla from the orbit and is sutured ventrally to the posterior process of the maxilla. Anterior to the jugal, the lacrimal is sutured to the dorsal edge of the maxilla. An anterior process of the maxilla wedges out between the nasal, septomaxilla and premaxilla just ventral to the narial opening. All of the upper cheek teeth are implanted in the maxilla. However, most of the anterior half of the bone is edentulous, so there is a long diastema between the cheek teeth and the large tooth in the premaxilla.

This diastema is formed from the posteroventral process of the premaxilla and the anterior portion of the maxilla between the incisors and the cheek teeth (Figures 3-5). The diastema is nearly as long $(\sim 80 \%)$ as the maxillary tooth row and is $22 \%$ of the skull length. The premaxilla and maxilla arch upward, and the corresponding portion of the dentary arches gently downward, thereby increasing the gape of the diastema.

The vomers are visible in the roof of the mouth along the dorsal surface of the diastema. They are sutured to the maxillae dorsally and to the premaxillae anteriorly. The vomers are thus narrow, rectangular bones sutured to each other at the midline. Each bears a tiny field of vomerine teeth, described below.

The orbit is nearly round, measuring $38 \mathrm{~mm}$ in both length and height. Because of compression, part of the dorsal skull roof (mostly the frontal 

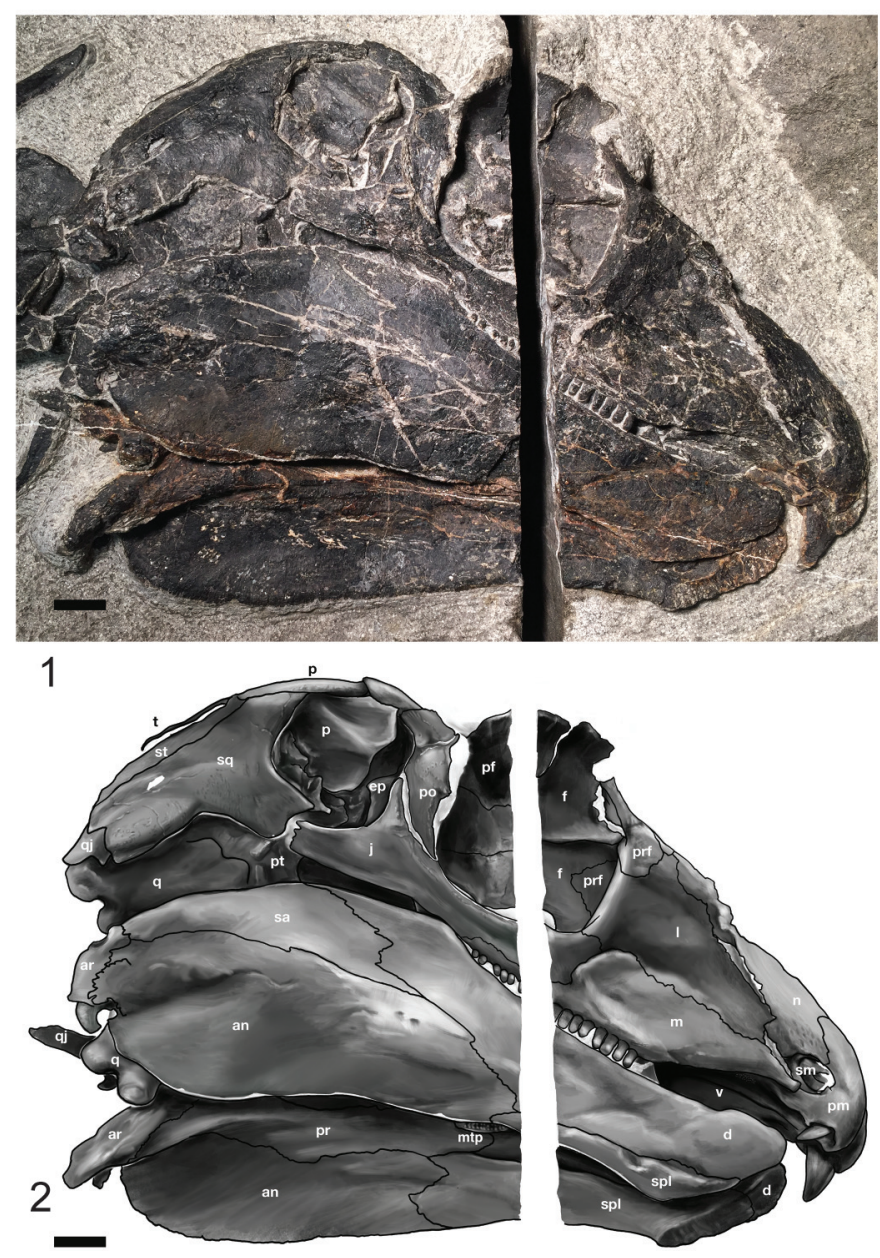

FIGURE 3. The skull and lower jaw, as preserved, of the holotype of Gordodon kraineri, NMMNH P-70796, in right lat-

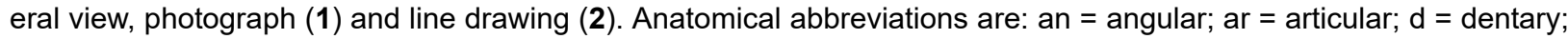

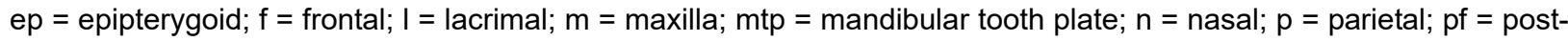
frontal; pm = premaxilla; $p r=$ prearticular; $p r f$ = prefrontal; $p t=$ pterygoid; $q$ = quadrate; $q j$ = quadratojugal; sa = surangular; sm = septomaxilla; spl = splenial; $\mathrm{sq}=$ squamosal; $\mathrm{st}=$ supratemporal; $\mathrm{t}=$ tabular; $v=$ vomer. Scale equals 1 $\mathrm{cm}$.

bones) has been folded down to form an interior wall to much of the right orbit. Thus, the midline suture between the frontals can be seen as a nearly horizontal ridge in the anterior half of the orbit (Figure 3). The lateral lappet of the frontal is flattened above the orbit and remains broad throughout its length, making up $\sim 25 \%$ of the dorsal margin of the orbit, with sigmoidal sutures to both the prefrontal and postfrontal. The lateral expansion of these three bones creates a transversely broad skull roof that would have overhung the orbit, as in Edaphosaurus (Modesto, 1995). The postero-dorsal portion of the orbital wall is composed of a large, trapezoidal postfrontal. The remainder of the posterior margin of the orbit is formed by the postorbital, which pinches out ven- trally between the jugal and the postero-ventral edge of the orbit.

The postorbital forms a small part of the dorsal edge of the skull roof immediately posterior to the orbit, and it forms the anterodorsal margin of the temporal fenestra. The jugal is sutured to the ventral margin of the postorbital. The jugal has an anterior process that extends ventral to the orbit and anteriorly to its suture with the lacrimal and maxilla. A shorter and taller posterior process of the jugal extends to under the anterior half of the ventral edge of the temporal fenestra. Ventral to the jugal, the epipterygoid is visible as a horizontal plate of bone. It has a dorsal process that projects into the anterior edge of the temporal fenestra as a thin flange of bone with a dorsally pointed tip. 


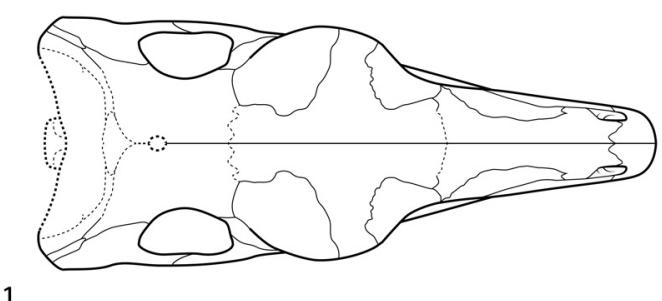

1

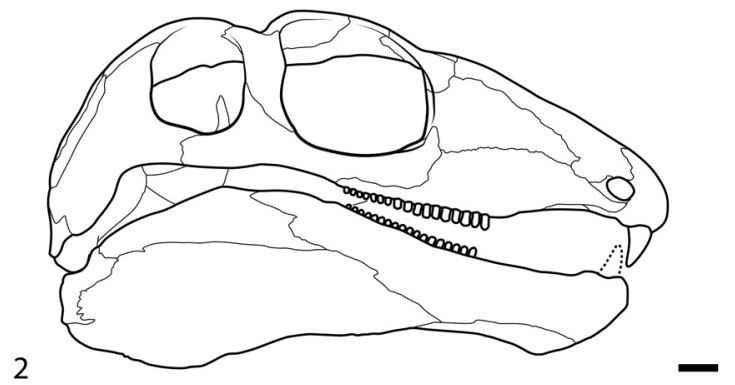

FIGURE 4. Reconstructed skull of Gordodon kraineri in dorsal (1) and right lateral view (2). Scale equals $1 \mathrm{~cm}$.

The parietal forms the dorsal margin of the temporal fenestra posterior to the postorbital. The parietals form most of the skull roof posterior to the orbits. The parietal is inferred to have articulated with the supratemporal, tabular and postparietal dorsally and can be seen to articulate with the squamosal ventrally. Much as is the case with the orbit, deformation of the skull has folded the parietals down so that they fill much of the right temporal fenestra. The temporal fenestra is square to round in shape, noticeably smaller than the orbit, and it is perceptibly taller $(28 \mathrm{~mm})$ than long $(25$ $\mathrm{mm}$ ).

The squamosal is a triradiate bone that forms the posterior concave margin of the temporal fenestra. It articulates to the parietal just posterior to the postero-dorsal edge of the fenestra. Its anterior process is sutured to the jugal, forming the posterior portion of the ventral edge of the temporal fenestra. The posterior process of the squamosal is sutured to the quadratojugal. Posterior to that suture, the posterior edge of the squamosal has a long and nearly straight suture with the supratemporal.

What little can be seen of the pterygoid is just ventral to much of the anterior process of the squamosal. It is sutured to the epipterygoid anteriorly and to the quadrate posteriorly.

The quadrate forms the postero-ventral corner of the skull. It is partly separated from the squamosal by a small quadratojugal. The quadratojugal is antero-posteriorly short and largely covered laterally by the squamosal. The posterior end of the
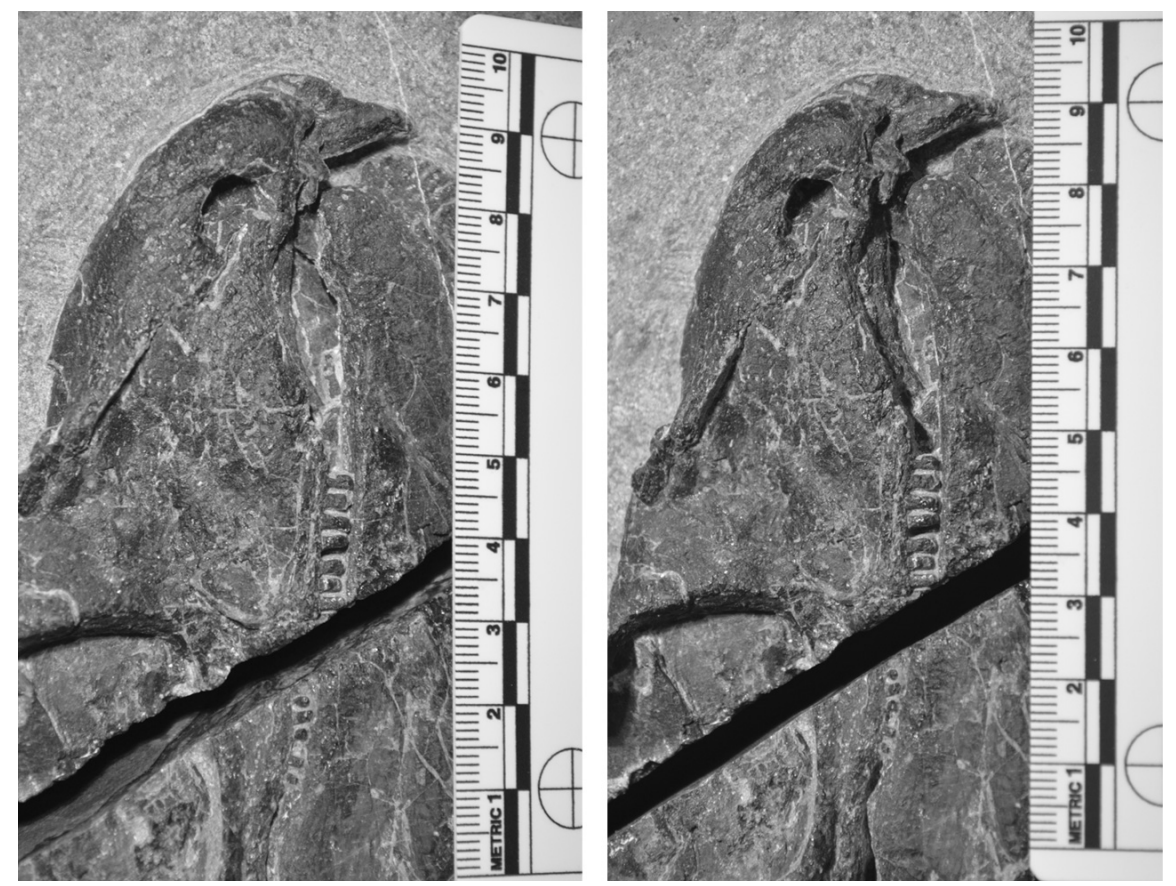

FIGURE 5. Stereophotograph of the snout region of NMMNH P-70796, holotype of Gordodon kraineri. Scale in cm and $\mathrm{mm}$. 
quadrate is a relatively small, knob-like process for articulation with the lower jaw. This articulation is clearly observed on the left side of the skull where the quadrate is preserved in articulation with the articular bone of the lower jaw (Figure 3).

Lower jaw. Because of medio-lateral compression and resulting distortion of the fossil, both sides of the lower jaw of NMMNH P-70796 are visible, the entire right side in labial view and much of the left side in lingual view (Figure 3 ). Total length of the lower jaw is $140 \mathrm{~mm}$, and it is $43 \mathrm{~mm}$ high at the coronoid process. Tooth row length is $\sim 78 \mathrm{~mm}$, of which $36.8 \mathrm{~mm}$ is the length of the cheek tooth row. The diastema is $\sim 33 \mathrm{~mm}$ long.

In labial view, the dentary makes up most of the anterior half of the lower jaw. It is edentulous between the cheek teeth and the incisor, which creates a long dentary diastema. Labially, the ventral edge of the anterior half of the dentary is excluded from the ventral margin of the jaw by the splenial along a long and slightly irregular suture. Posterior to this suture, the dentary forms the upper part of the medial surface of the jaw as far as the coronoid region and has a long ventral suture with the angular (anteriorly) and surangular (posteriorly).

The splenial is a long, thin bone with a ventral edge that is slightly thickened. On the labial side of the jaw, the splenial sutures to the dentary dorsally and to the angular posteriorly. However, on the lingual aspect of the jaw, the posterior portion of the splenial overlaps the dentary so that it has a more extensive suture with the angular and also contacts the prearticular.

Both the splenial and the dentary contribute to a short (25 mm long) and unfused mandibular symphysis. The front end of the lower jaw is shallow, reaching a maximum height of $20 \mathrm{~mm}$ at the posterior end of the symphysis, where the splenial is ventrally deflected to form a shallow "chin."

Most of the remaining labial aspect of the lower jaw is composed of the angular, which wedges out anteriorly between the dentary and the splenial. Posterior to that, the angular flares out to a be a large, almost teardrop-shaped bone that occupies most of the postero-ventral portion of the lower jaw. It is sutured dorsally over most of its length to the surangular and posteriorly to the articular. Lingually, the prearticular covers part of the posterior portion of the dentary and overlaps part of the dorsal portion of the angular.

Posterior to the dentary and dorsal to much of the angular is the surangular. It has an anterior tip that projects into the dentary ventral to a long, irregular surangular-dentary suture. The posterior end of the surangular is sutured to the articular posteriorly and the angular ventrally. The deepest point of the lower jaw-46 mm-is just posterior to the dentary-surangular suture. The postero-dorsal part of the dentary and surangular thus form a prominent coronoid eminence.

The articular is a narrow bone that wraps around part of the posterior end of the lower jaw. Its postero-dorsal edge includes a low concavity that articulates with the quadrate, forming the jaw joint.

Dentition. We divide the dentition of Gordodon into five visible portions and one portion that we infer to be present but cannot directly observe: (1) incisors; (2) maxillary cheek teeth; (3) dentary cheek teeth; (4) vomerine teeth; (5) pterygoid teeth (not visible); and (6) mandibular tooth plate. Measurements of the cheek teeth are tabulated (Table 1).

Incisors: A single, large incisor is present in each premaxilla. It is a trenchant tooth with a pointed tip that is $11.4 \mathrm{~mm}$ tall and $8.1 \mathrm{~mm}$ wide at the crown base. The right incisor is not complete; only a splinter-like fragment of the tooth remains (Figures 3, 5). The left incisor appears to be complete. In mesiodistal view (we use the terminology of Peyer, 1968), the anterior surface is shorter and more acutely curved than the posterior surface, resulting in a very anteroposteriorly wide crown base. The base of the incisor crown is approximately five times the anteroposterior width of the largest cheek teeth. Measured at its anteroposterior centerline, the crown height of the incisor is three times greater than that of the largest cheek tooth. The incisor is not visible in anterior aspect, but appears to be very narrow-possibly flattened or simply broken so that only a narrow portion remains. However, there is a morphometric method to deduce the shape of the incisor in anterior view.

Rinehart and Lucas (2013) demonstrated that in a variety of vertebrates, from fish to humans, non-crushing teeth (i.e., not molars, but teeth that bite into something) that have a triangular shape in labial view show a cubic parabolic strength profile in which strength varies as height ${ }^{3}$. In contrast, teeth that have a rectangular shape in labial view show a parabolic strength profile in which strength varies as height ${ }^{2}$ (height is the distance above the crown base). This is probably a general rule. Thus, by observing the shape of the strength profile, the shape of the tooth in labial view may be indicated.

The incisor of Gordodon presents its shape in mesiodistal view (Figures 3, 5). From measurements of the incisor in this view we calculate the relative labiolingual strength (resistance to bending 
TABLE 1. Measurements of the cheek teeth of the holotype of Gordodon kraineri, NMMNH P-70796.

\begin{tabular}{ccc}
\hline Cheek Tooth & $\begin{array}{c}\text { Length } \\
\text { (crown height) } \\
\text { (mm) }\end{array}$ & $\begin{array}{c}\text { Width } \\
\text { (anteroposterior) } \\
\text { (mm) }\end{array}$ \\
\hline 2 & 3.5 & 1.8 \\
3 & 3.4 & 2.2 \\
4 & 3.7 & 2.0 \\
5 & 3.4 & 1.7 \\
6 & 3.3 & 1.9 \\
7 & 3.7 & 2.0 \\
8 & incomplete & incomplete \\
$9, \sim 10, \sim 11$ & missing (saw cut) & \\
$\sim 12$ & incomplete & incomplete \\
$\sim 13$ & 2.1 & 1.4 \\
$\sim 14$ & 2.1 & 1.4 \\
$\sim 15$ & 1.5 & 1.5 \\
$\sim 16$ & missing & 1.4 \\
$\sim 17$ & 1.5 & 1.4 \\
$\sim 18$ & 1.3 & 1.5 \\
\hline
\end{tabular}

or breaking) profile (Figure 6). The circle data points with the solid line curve fit in the figure shows the labiolingual strength (circles) as a function of height above the crown base in relative units.

Height $^{2}$ (squares, short dashes) and height ${ }^{3}$ (triangles, longer dashes), both scaled to the strength curve, are also plotted (Figure 6). Obviously, the height ${ }^{2}$ curve is a reasonable fit to the strength profile curve, and the height ${ }^{3}$ curve is much less so. The tip of the tooth is somewhat rounded, either by wear or taphonomic processes. If it were pointed, as it probably was in life, the strength profile curve would be shifted so as to be an even better fit to the height ${ }^{2}$ curve. We conclude that, as one would expect of a cropping tooth, the Gordodon incisor almost certainly had a chisel-like, near-rectangular shape in anterior (labial) view.

With respect to the mandibular incisors, a single, shallow depression exists on the dorsal side of the anterior end of the right dentary that represents a tooth emplacement pit. Preparation was extended under the anterior end of the right mandible in an effort to discover whether the left mandible had an incisor, and no incisor was found. However, because the right dentary shows an apparent incisor emplacement pit, we conclude that Gordodon had two large lower incisors, one in each dentary, but they are not preserved in NMMNH P-70796.
Maxillary and dentary cheek teeth: 12 complete, relatively small and peg-like maxillary teeth are present together with one empty emplacement (position 16, Table 1) (Figures 3-5). Two teeth are incomplete, portions of them being lost to the saw cut through the skull, and approximately three are missing in the saw cut. Thus, a total of 18 maxillary teeth would have been present in the specimen. The first eight (anteriormost) cheek teeth are larger than the six posterior ones, but the transition between the two sizes occurs within the space of the saw cut, so it is uncertain whether the transition is gradual or abrupt.

The first eight maxillary cheek teeth are approximately two times longer (taller) than their maximum diameters and are very slightly bulbous in shape. The diameters of these teeth range from $1.7 \mathrm{~mm}$ to $2.2 \mathrm{~mm}$, in no particular size order along the tooth row, and average $1.9 \mathrm{~mm}$. The crown tips are dome-like; no cingula, cusps, or other features are evident.

The six posteriormost teeth are simple, short pegs with dome-like tips. Their diameters are slightly smaller than those of the anterior teeth and are approximately equal to their lengths. These teeth decrease slightly in size toward the distal end (toward the jaw joint) of the tooth row.

A single dentary cheek tooth is exposed in a gap between maxillary teeth 4 and 5 . It appears identical to the maxillary teeth. The remainder of the dentary cheek teeth are covered and not visible. However, the dentary tooth row is unlikely to have been longer than that of the maxillary.

Vomerine teeth: Numerous very small (much less than $1 \mathrm{~mm}$ in diameter) conical teeth are present on the vomers (Figures 3,5 ). These tiny teeth are located in an anteroposteriorly elongate grouping along the medial edges of the vomers, near the center of the diastema, approximately halfway between the incisors and the cheek teeth. They appear to be distributed in a random pattern. Most of the surface of the vomers is smooth and edentulous.

Pterygoid teeth: The pterygoid teeth are completely covered in NMMNH P-70796. Presumably, as in Edaphosaurus (e.g., Modesto, 1995), they are of similar size and shape to the opposing mandibular tooth plate teeth, forming an effective mill for grinding vegetation.

Mandibular tooth plate. A ventral portion of the mandibular tooth plate is exposed on the prearticular of the left mandible just beneath the ventral edge of the right mandible (Figure 3). It likely extends up onto the surangular and coronoids, as 


\section{Strength profile of Gordodon incisor}

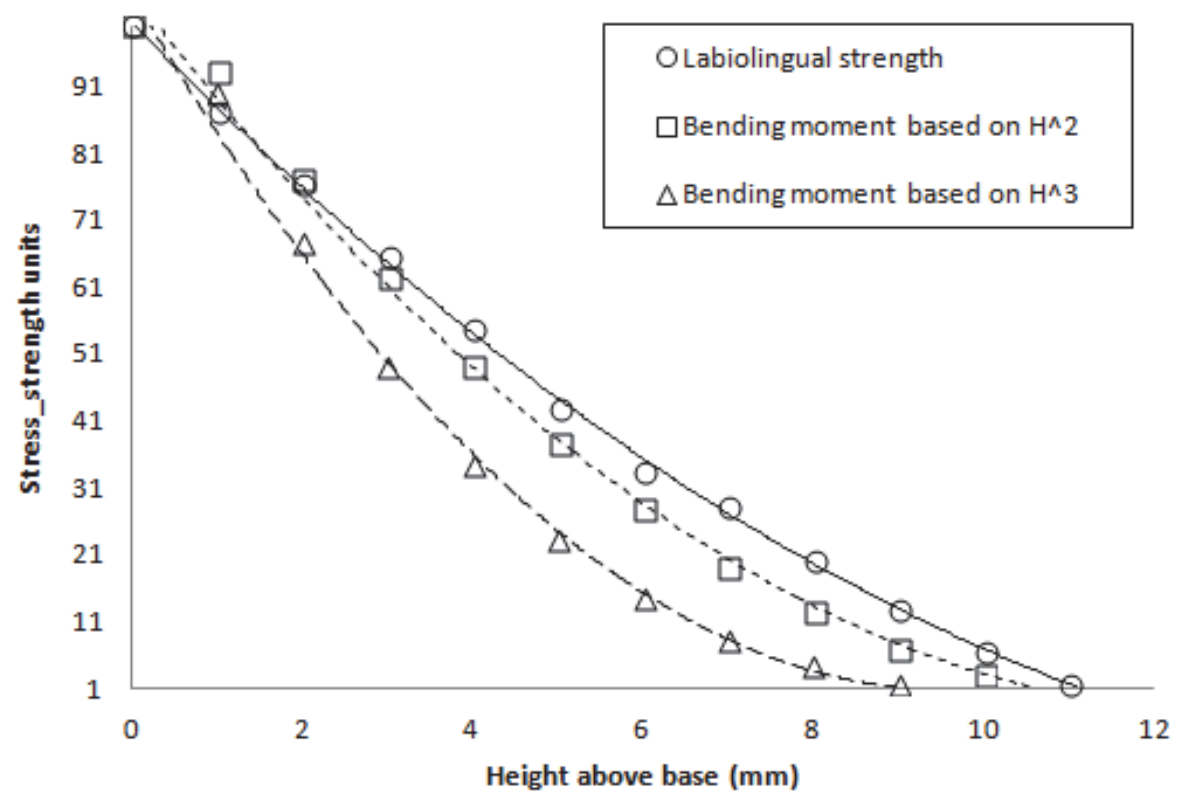

FIGURE 6. Labiolingual strength profile of the Gordodon incisor in relative units. Circles with solid line curve fit shown with bending moment curves based on height ${ }^{2}$ (squares with short dash line) and height ${ }^{3}$ (triangles with long dash line) scaled for comparison to the strength profile curve.

it does in Edaphosaurus (e.g., Modesto, 1995). Almost all of the tooth plate is concealed by the right mandible.

The lower edge of the tooth plate is rounded. The small exposed area of the tooth plate is $15 \mathrm{~mm}$ long and has a maximum width of $3 \mathrm{~mm}$. Treating it as a circular segment with a chord length of $15 \mathrm{~mm}$ and width of $3 \mathrm{~mm}$, the exposed area is $\sim 31 \mathrm{~mm}^{2}$. Within the exposed area, 26 tiny teeth are present; an average of 0.84 teeth per $\mathrm{mm}^{2}$.

Vertebral column. NMMNH P-70796 preserves all or parts of 21 vertebrae (Figures 2, 7). There are five cervical vertebrae based on rib morphology (cf. Romer, 1956), which is described below. Cervical vertebrae two through four are essentially complete, well preserved and well exposed. Vertebrae five (last cervical) through nine (anterior four dorsals) are slightly weathered and are not as fully exposed due to overlying rib fragments. Vertebrae 10 through 12 show progressively poor preservation; they are weathered and incomplete. Number 13 consists of an approximately complete neural arch and neural spine, and numbers 14 through 21 are represented only by incomplete neural spines.

Nineteen neural spines thus represent the preserved "sail" of Gordodon. Romer and Price
(1940) note that most eupelycosaurs have 27 presacral vertebrae, so this suggests that most of the presacral series of Gordodon is preserved. The spines of the first 11 vertebrae can be seen to be sutured to the centra. Posterior to vertebra 11, no centra are preserved, so the spines are incomplete proximally. All of the spines are flattened medio-laterally so that along most of their length they have a subrounded to rectangular cross section (the long axis of the rectangle is oriented antero-posteriorly). However, near their distal ends, all of the spines are further compressed to be blade-like in cross section. Each spine also bears numerous, irregularly spaced tubercles (cross bars) that project laterally from the spine. Unlike Edaphosaurus, in which the tubercles are thick and blunt-tipped, those of Gordodon are thin, have pointed tips and are often curved. Also, unlike Edaphosaurus, there is no indication of an elongate "cruciform" transverse process near the base of the neural spines. The tubercles of Gordodon are $3-5 \mathrm{~mm}$ long and $1-1.5 \mathrm{~mm}$ in diameter. On several of the spines, some of the tubercles of the left side remain concealed by matrix, and on some spines some of the tubercles on the right side have been worn off by abrasion, leaving only their bases. 


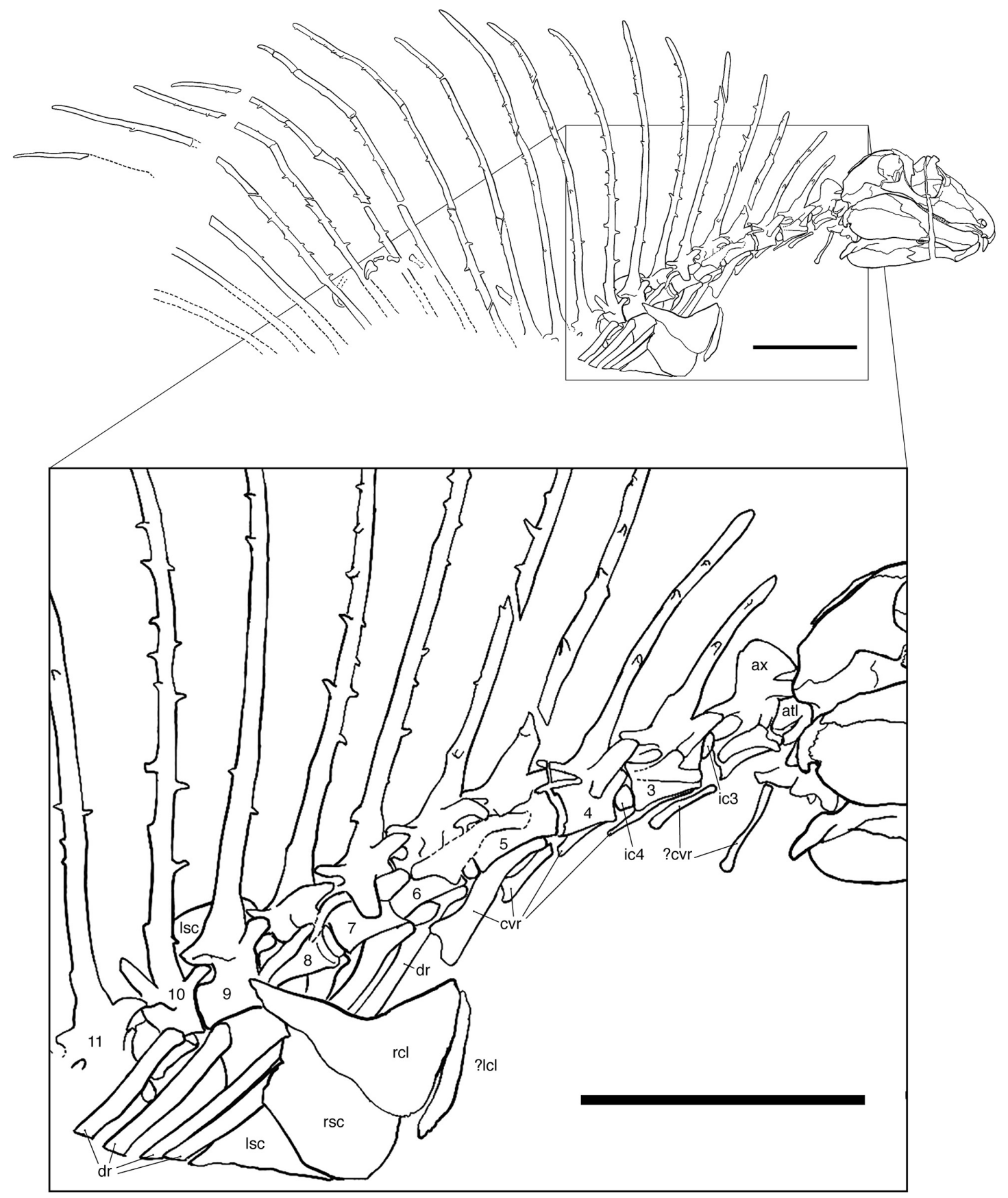

FIGURE 7. Interpretive drawing of NMMNH P-70796. Anatomical abbreviations are: atl = atlas; $a x=a x i s ; c v r=c e r v i-$ cal ribs; $d r$ = dorsal ribs; Icl/rcl = left/right clavicle; Isc/rsc = left/right scapulocoracoid; ph = ?manual phalanges. Scale bars equal $10 \mathrm{~cm}$.

The lengths of the centra (= pleurocentra) and intercentra are tabulated (Table 2) and plotted (Figure 8.1). In the preserved vertebrae, the ratio of intercentrum length/centrum length decreases moving posteriorly along the vertebral column (Table 2, column IC/PC), i.e., the intercentrum becomes relatively shorter compared to the centrum. The intercentrum decreases from $\sim 24 \%$ of centrum length in vertebra number 2 to $\sim 15 \%$ of centrum length in vertebra number 10 (Figure 8.2). Neural spine lengths, measured from the bases of the pedicles, along the curvature of the element, to 
TABLE 2. Vertebral metrics of the holotype of Gordodon kraineri, NMMNH P-70796, in mm. LC = maximum length of the centrum, post $\mathrm{HC}=$ posterior height of the centrum, Post $\mathrm{H}=$ height from lower edge of posterior centrum to top of postzygapophyses, LIC = length of the intercentrum, NS length = length of the neural spine measured from pedicle base to tip along its curve.

\begin{tabular}{|c|c|c|c|c|c|c|c|c|}
\hline Zone & $\begin{array}{l}\text { Vertebra } \\
\text { number }\end{array}$ & LC & Post HC & Post H & LIC & NS length & LIC/LC\% & Post HC/LC \\
\hline cervical & 2 & 27.9 & 15.1 & 26.3 & 6.7 & 15.5 & 24.01 & 0.54 \\
\hline cervical & 3 & 29.6 & 17.8 & 28.9 & & 75 & & 0.60 \\
\hline cervical & 4 & 29.4 & 19 & 28.2 & 6.5 & 116 & 22.11 & 0.65 \\
\hline cervical & 5 & 28.3 & 19.5 & 29.7 & 6.1 & 134 & 21.55 & 0.69 \\
\hline dorsal & 6 & 28.2 & & 31.9 & 5.9 & 183 & 20.92 & \\
\hline dorsal & 7 & 28.2 & 15.2 & 31.9 & & 217 & & 0.54 \\
\hline dorsal & 8 & 27.1 & & & 5.3 & 244 & 19.56 & \\
\hline dorsal & 9 & 27.5 & 15.7 & 27.9 & 4.5 & 271 & 16.36 & 0.57 \\
\hline dorsal & 10 & 27.4 & 15.4 & & 4.1 & 298 & 14.96 & \\
\hline dorsal & 11 & 26.8 & & & & 314 & & \\
\hline dorsal & 12 & & & & & 348 & & \\
\hline dorsal & 13 & & & & & & & \\
\hline dorsal & 14 & & & & & 410 & & \\
\hline
\end{tabular}

the distal tip are tabulated (Table 2) and plotted (Figure 9.1).

In Gordodon, the centrum is the main vertebral body, and the centra are essentially cylindrical with slightly inflated ends. In general, they are amphicoelous and notochordal. The best preserved and exposed (numbers 2 through 9) show double ventral keels that border a median concavity (sulcus) on the ventral surface of the centrum. An embayment in the anteroventral surface of each centrum completely contained the intercentrum. The posterior faces of the centra are perpendicular to the longitudinal axis and are not curved, angled or sculpted to accommodate the intercentra.

The intercentra are nearly cylindrical in shape, with a slightly excavated ventral surface in the anteroposterior direction (Figure 7). The capitular rib facets (parapophyses) are located on the posterolateral intercentra.

Twelve complete neural arches are preserved on vertebrae 2 through 13 . They are connected to the centra by means of semicircular pedicles. The prezygapophyses extend anteriorly past the anterior end of the centrum, whereas the postzygapophyses extend to a plane approximately even with the posterior end of the centrum. Thus, the articulation of the zygapophyses is located above the posterior end of each centrum. Transverse processes are placed anterolaterally on the bases of the neural arches and bear the tubercular rib facets (diapophyses) (Figure 7).
Neural spines posterior to the atlas-axis complex are extremely elongate (Table 2, Figure 9.1), anteroposteriorly subround to subrectangular in cross section and have blunt, rounded distal tips that are blade-like in cross section. The proximal $2-3 \mathrm{~cm}$ of the neural spine is inflated where it connects to the neural arch. Neural spine 13 is broken a few $\mathrm{cm}$ from its distal end, and the broken ends overlap, so its complete length is not apparent. Neural spines 2, 3 and 4 curve anteriorly, neural spine 7 is essentially straight, and all neural spines posterior to 7 have a distinct posterior curvature of their distal ends (Figure 2).

Atlas-axis complex: The atlas is present, but is disarticulated, and except for the centrum, is mostly covered by the occiput of the skull and the right mandible (Figure 7). Thus, no proatlas can be seen, and only the posterior part of the atlantal centrum is visible as a trapezoidal and slightly concave (in lateral view) bone ventral to the anterior zygapophysis of the axis. This bone is likely seen ventrally, having been twisted around its long axis. Its dorsal edge is a slightly convex flange of bone that is slightly separated from the ventral edge of the anterior zygapophysis of the axis. Ventral to the atlantal centrum a bone can be seen laterally as an anterior-posterior rectangle covered in part by a rib. We identify this bone as the axis intercentrum. This is consistent with identification of the overlying, rectangular bone as the atlantal centrum.

The axis is well preserved and well exposed. Its centrum is in life position, but its intercentrum is 

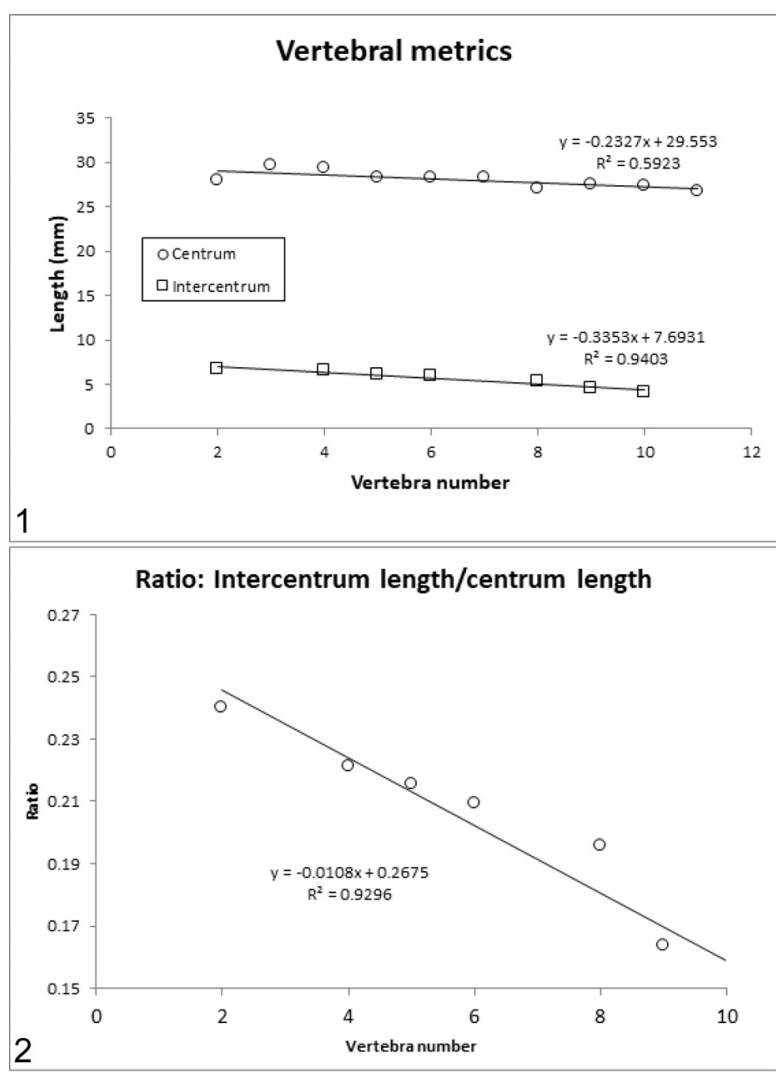

FIGURE 8. Metrics and statistics of the vertebral column as preserved in the holotype of Gordodon kraineri, NMMNH P-70796. 1, Lengths (maximum anteroposterior extent, per Romer and Price, 1940) of the intercentra and centra of vertebrae two through 10, showing monotonic decrease in the length of both elements over the range. 2, Ratio of intercentrum to centrum length (\%) decreases from vertebra number two through number 10 as shown by the negative slope of the curve fit, i.e., centrum length decreases at a higher rate than intercentrum length; proceeding posteriorly along the vertebral column the intercentrum becomes relatively longer.

displaced. The axial centrum is long, spool shaped and amphicoelous. The centrum is slightly constricted (waisted). Part of its cervical rib has been pushed against the lateral side of the axis centrum, so that its distal end is confluent with the posterodorsal end of the centrum. The neural arch shows well-developed pre- and postzygapophyses. These are relatively long and thin flanges of bone that project anteriorly and posteriorly (respectively) from the top of the neural arch. The prezygapophyses are at least as long as in the other cervical and dorsal vertebrae, but appear thinner and less robust. In lateral view, the neural spine is short, wide and slightly hatchet shaped (trapezoidal). It is anteriorly canted so as to nearly contact the poste- rior end of the skull, which has evidently been displaced backward.

Posterior cervical vertebrae: Cervical vertebra 3 has a centrum similar to that of the axis but deeper (taller). Intercentrum 3 is a rectangular bone between the axis and cervical 3 that has been rotated and displaced dorsally to lie between the two centra. The pre- and postzygapophyses of cervical 3 are similar to those of the axis in being long flanges that project anteriorly and posteriorly above the neural canal. The neural spine of cervical 3 is short, inclined anteriorly, and only the broken base of one tubercle is present on the right side. From its wide base of attachment to the centrum, it narrows rapidly to a bluntly pointed tip that is slightly inflected posteriorly.

The centrum of cervical 4 is deeper and thus more square in lateral view than that of cervical 3 , but otherwise similar. Intercentrum 4 is a semicircular bone displaced to be located between the articular surfaces of cervicals 3 and 4 . Unlike the zygapophyses of cervical vertebrae 2 and 3 , those of cervical 4 are more dorsally directed, so they project from the neural arch at an angle of about 450. A fracture through the fossil and matrix slightly separates the posterior portion of centrum 4 from the rest of the centrum. The neural spine of cervical 4 is about 1.5 times as long as that of cervical 3 . It is also inclined anteriorly and has three tubercles visible on the right side and two on the left. The spacing of these tubercles relative to each other is irregular, and they are not aligned from the right to left side but instead offset (staggered; see later discussion). Because the right side of the animal is more fully prepared, the tubercle counts on the right should accurately represent the number present in the animal. The actual numbers of left side tubercles are underrepresented in this description because many are covered.

Cervical 5 is larger than but very similar to cervical 4. The neural spine of cervical 5 is inclined forward but not curved anteriorly, as are the spines of cervicals 3 and 4 . This spine is slightly longer than the spine of cervical 4 . There are four tubercles visible on the right side that show irregular spacing.

Dorsal vertebrae: The shape of the centrum of the first dorsal vertebra is much shorter and taller (more square in lateral view) than the cervical centra. The base of the neural arch (pedicle) is also taller, and the pre- and post-zygapophyses are shorter and more antero-posteriorly directed (they project from the neural spines at an angle of only $10^{\circ}$ ). The intercentrum between the last cervical 
and the first dorsal vertebra is a wedge-shaped bone displaced dorsally so it is directly posterior to the posterior articular surface of cervical 5 . The neural spines to cervicals 3,4 and 5 have an antero-posteriorly expanded proximal end that is sutured to each centrum. However, the neural spine of dorsal 1 (and the dorsal vertebrae posterior to it) does not have this expanded proximal portion. Instead, their proximal ends are of essentially the same diameter as the remainder of the spine. The neural spine of dorsal 1 is nearly straight, and it is much longer than the spine of cervical 5 . The spine of dorsal 1 bears 7 tubercles on its right side-the bases of three proximally and four more complete tubercles distally.

The intercentrum between dorsal vertebrae 1 and 2 is a rounded, blocky bone ventral to the posterior end of the centrum. Dorsal vertebra 2 is slightly larger but essentially identical to dorsal vertebra 1 in its central, neural arch and zygapophyseal morphology. The neural spine of dorsal 2 is slightly longer than that of dorsal 1 . It is slightly inclined forward but, like the spines of cervicals 3 and 4 , nearly straight. It has seven tubercles on the left side, and the bases of eight tubercles on the right side. This spine has a subrounded to rectangular cross section from its proximal end through the 5th tubercle and then a blade-like distal cross section.

No intercentrum can be seen between dorsal vertebrae 2 and 3 . Dorsal vertebra 3 is slightly larger than but essentially identical to dorsal vertebra 2 in its central, neural arch and zygapophyseal morphology. Its neural spine is similar to that of dorsal 2 but longer. It has 11 (the proximal two are broken) tubercles on the right side and six tubercles visible on the left side. The distal portion of this neural spine is curved posteriorly.

Dorsal vertebra 4 is slightly larger but essentially identical to dorsal vertebra 3 in its central, neural arch and zygapophyseal morphology. The neural spine of dorsal 4 is longer than that of dorsal 3 but otherwise similar. It has one tubercle visible on the left side and nine, mostly broken, tubercles on the right.

Dorsal vertebrae 5 and 6 are weathered and overlapped by ribs. Dorsals 7 and 8 preserve only parts of their centra and zygapophyses. They seem to be very similar to the central, neural arch and zygapophyseal morphology of dorsal 4 . The neural spine of dorsal 5 is also slightly longer and similar to that of dorsal 4 , but shows eight tubercles on the left side and 11 on the right. The neural spine of dorsal 6 is longer yet, but the tubercles are not well preserved; there are at least 12 , mostly broken, tubercles on the right side. The neural spine of dorsal 7 continues the increase in length and has 10 tubercles (mostly broken) on the right side. The neural spine of dorsal vertebra 8 is much like that of dorsal 7. It is the most posterior vertebra in which at least some of the centrum and the attachment of the neural spine to the centrum is preserved. Nine, mostly broken, tubercles are preserved on the right side.

The neural spine of dorsal vertebra 9 is much longer than that of dorsal 8 . It has five tubercles on the left side and 12 visible on the right.

The neural spine of dorsal vertebra 10 is incomplete but appears to be approximately the same length as that of dorsal vertebra 9. It displays at least six broken tubercles on the right side and one on the left.

The neural spine of dorsal vertebra 11 is also incomplete and is broken and offset about onethird of the length from its distal tip. It has eight tubercles on the right side, and three visible on the left.

The neural spine of dorsal vertebra 12 is incomplete, and there is a break and kink in the spine about one-third of the distance from its distal tip. It has four tubercles visible on the left side and seven on the right.

Dorsal vertebra 13 has a neural spine that is longer but eroded in places. It displays 5 tubercles on the left side and 2 on the right.

The neural spine of dorsal vertebra 14 is the longest neural spine. It is eroded and incomplete, as are the neural spines of dorsal vertebrae 15 and 16 , which exhibit very incomplete proximal portions of the spines.

Size and spacing of neural spine tubercles: Except on the atlas-axis complex, laterally-directed tubercles project from all of the neural spines of Gordodon. Most bend slightly downward. Tubercle lengths and diameters are randomly associated. Thus, a longer or shorter tubercle will not necessarily have a correspondingly larger or smaller diameter (Figure 9.2). Neither does the position along the length of the neural spine predict tubercle size (Figure 10.1). Tubercle diameters and lengths are randomly distributed along the length of the neural spines.

The spacing between tubercles is normally distributed (Gaussian) over the range of 7 to 31 $\mathrm{mm}$ with a mean value $(\mu)$ of $17.3 \mathrm{~mm}$ and a standard deviation $(\sigma)$ of $6.7 \mathrm{~mm}(\mathrm{~N}=36)$ (Figure 10.2). As the spacing is completely random and independent on the right and left sides, there is no ten- 


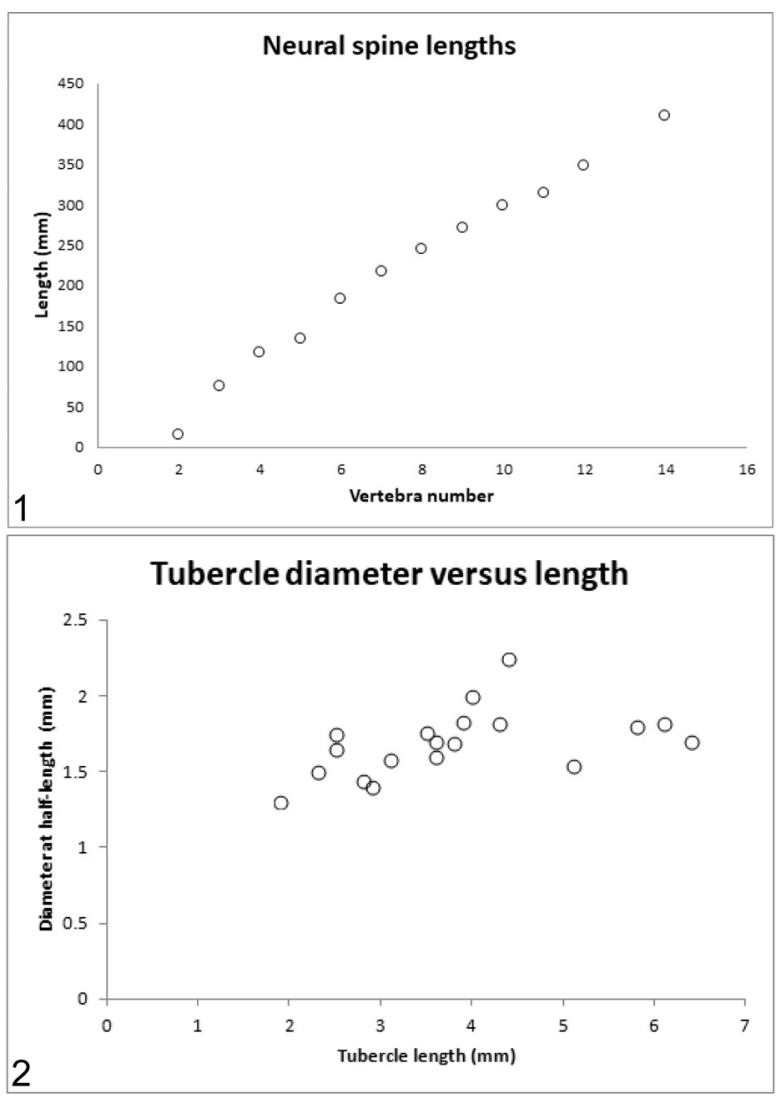

FIGURE 9. Metrics and statistics of the vertebral column as preserved in the holotype of Gordodon kraineri, NMMNH P-70796. 1, Neural spine length increases moving posteriorly along the vertebral column for at least the first 14 vertebrae. 2, Scatterplot of tubercle diameter (measured at $1 / 2$ length) as a function of length. The relationship of diameter to length is very weak; diameter essentially cannot be predicted by length.

dency for the tubercles to be configured in opposing pairs along the neural spines. Rarely, by chance, they do form an opposing pair.

Tubercle lengths are distributed normally over a range of $1.9 \mathrm{~mm}$ to $6.4 \mathrm{~mm}(\mu=3.8 \mathrm{~mm}, \sigma=0.3$ $\mathrm{mm}, \mathrm{N}=19$ ) (Figure 11.1). The tubercle diameters vary from $1.4 \mathrm{~mm}$ to $2.2 \mathrm{~mm}$ at half length and are normally distributed along the length of the neural spines $(\mu=1.7 \mathrm{~mm}, \sigma=0.22 \mathrm{~mm}, \mathrm{~N}=19)$, i.e., there is no tendency for their diameters to be larger or smaller at any position along the length of the neural spines (Figure 11.2).

The distribution of the tubercles along the length of the neural spines appears random. We performed a statistical test to verify the nature of their linear distribution as either ordered (evenly spaced like fence posts); random (distributed randomly according to the Poisson probability distribu-

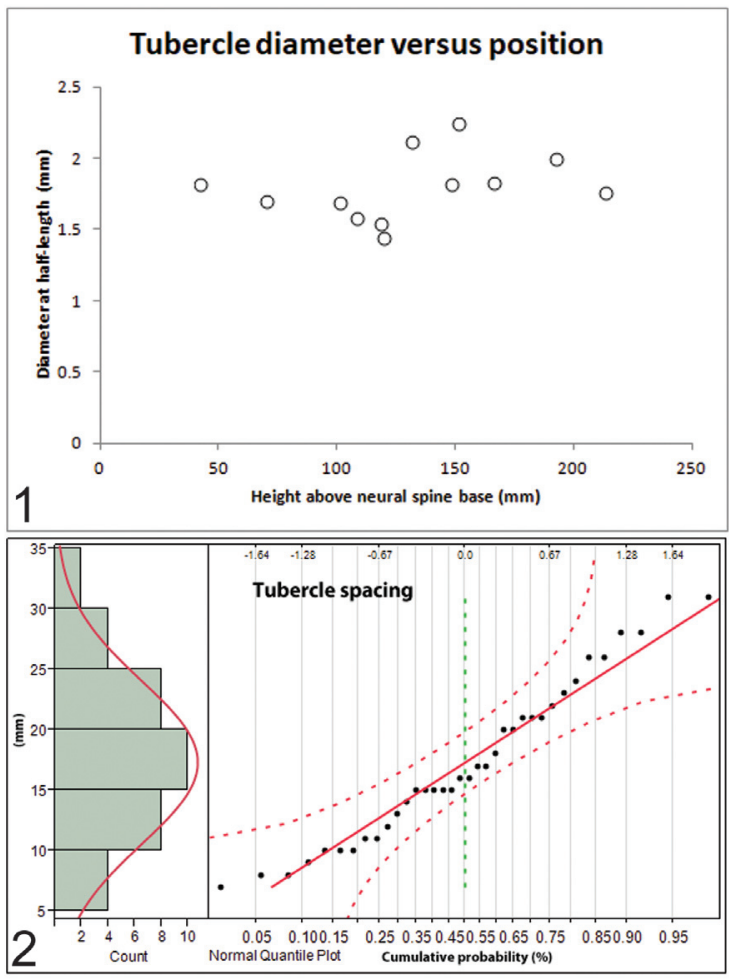

FIGURE 10. Metrics and statistics of the vertebral column as preserved in the holotype of Gordodon kraineri, NMMNH P-70796. 1, Tubercle diameter (measured at $1 / 2$ length) is not organized with respect to height above the base of the neural spine. Tubercle diameter cannot be predicted by position along the length of the neural spine. Data from neural spines 4, 7, and 10. 2, Tubercle spacing distribution: histogram with normal curve fit and cumulative probability plot with $95 \%$ normal confidence intervals. Spacing between tubercles is normally distributed, and they do not occur in opposing pairs except by random chance. Data from neural spines $4,7,8$, and 10. $\mathrm{N}=36$.

tion function); or aggregated, organized in closely packed clumps with empty spaces between (Figure 12.1).

A random distribution of events over an area or along a line (such as the occurrence of tubercles along a neural spine) is described by the Poisson distribution (Zar, 1999). Therefore, a Poisson distribution of a spatial data set may be taken as evidence of its random distribution. The equivalence of the mean and variance is a unique characteristic of the Poisson distribution that may be used as a test for its presence in a data set. Such a test may be performed by plotting the log-transformed mean versus the log-transformed variance of the number of events (tubercles) within line segments of varying size (along the length of the neural spines) (Hayek and Buzas, 1997; Zar, 1999). A similar 


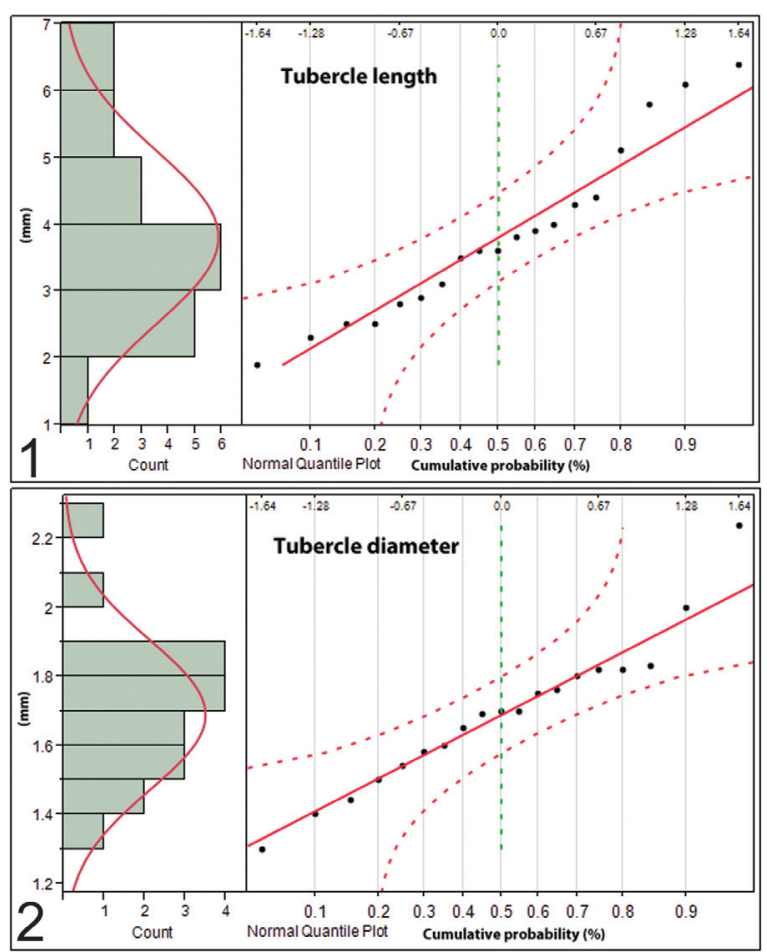

FIGURE 11. Metrics and statistics of the vertebral column as preserved in the holotype of Gordodon kraineri, NMMNH P-70796. 1, Tubercle length distribution: histogram with normal curve fit and probability plot with $95 \%$ normal confidence intervals. Tubercle lengths are normally distributed. Data from neural spines 4, 7, and 10 $\mathrm{N}=19.2$, Tubercle diameter distribution, measured at $1 /$ 2 length: histogram with normal curve fit and probability plot with $95 \%$ normal confidence intervals. Tubercle diameters are distributed normally. Data from neural spines 4,7 , and $10 . \mathrm{N}=19$.

approach has been used to determine the spatial distribution of fossil plant assemblages (e.g., DiMichele et al., 1996; Rinehart et al., 2015).

A regression line is fitted to the data, and its slope is observed. It is the slope of the lines, not their absolute values that is pertinent. High slopes $(>1)$ indicate aggregation (clumping), slopes on the order of one $(\sim 1)$ indicate a random (Poisson) distribution and low slopes $(<1)$ show ordering (Figure 12 ). In the assessment of spatial distribution, line segments are normally chosen so as to be of uniform size and to increase in size incrementally, as we did, although this is not necessarily essential (Hayek and Buzas, 1997). The test results show that the slope of the line is very close to one (0.947), indicating that the tubercles of Gordodon are truly randomly distributed along the neural spines (Figure 12.2). This random distribution of spine tubercles in Gordodon contrasts with the

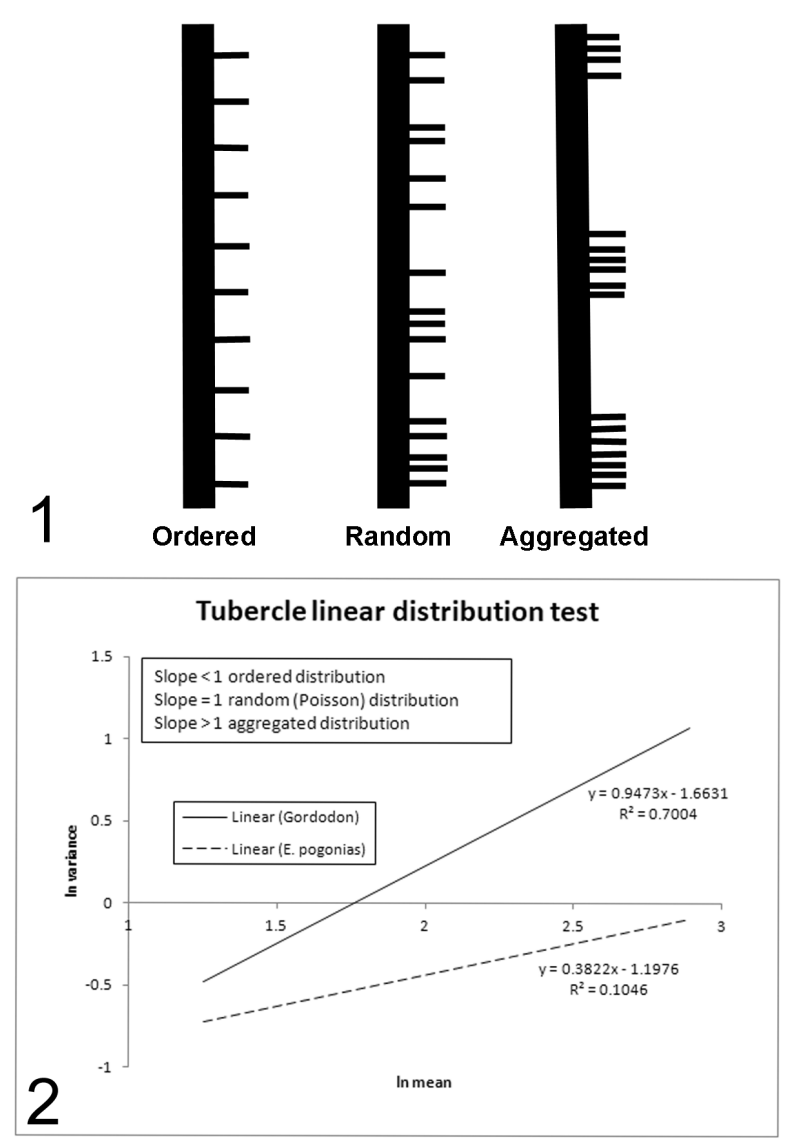

FIGURE 12. Distribution of tubercles along the length of the neural spines in Gordodon and Edpahosaurus. 1, Examples of linear distribution types: Ordered (equally spaced, like fence posts), Random (arranged according to the Poisson statistical distribution), and Aggregated (arranged in clusters with significant spaces between them). 2, Plot of natural logs of means and variances of data sets of distances between tubercles along the neural spines divided into $2,3,4,5,6,7$, and 8 equal length segments comparing the distribution of tubercles of Gordodon kraineri and Edaphosaurus pogonias. The slope of the lines, not their absolute values, is the pertinent factor: slope $<1$ indicates an ordered distribution; slope $=1$ indicates random (Poisson) distribution; slope $>1$ indicates aggregated distribution. Because of limited sample size, scatter in the data points was high (note low $\mathrm{R}^{2}$ numbers in the curve fit equations), but the results are clear. The slope of the Gordodon curve fit line is 0.95 , indicating a near-perfect Poisson distribution, whereas the slope of the E. pogonias curve fit is 0.38 , indicating a well-ordered distribution.

defined longitudinal rows on the neural spines of other edaphosaurids, and thus indicates greater variability in spine ornamentation among edaphosaurids than previously known. 
Ribs. All vertebrae preserved in NMMNH P-70796 bear ribs (Figures 2, 7). All except the atlantal ribs are proximally bifurcated. All right ribs, except those of the atlas, are fragmentary or missing; both atlantal ribs are complete and well exposed. Left ribs are preserved and reasonably well exposed, although the distal end of rib number 6 is covered by the shoulder girdle, and the distal ends of all subsequent ribs are missing (off the slab).

The possibility that the bones identified here as atlantal ribs (Figure 7) are hyoid elements (ceratohyals?) needs to be considered. No edpahosaurid hyoid elements have been described or illustrated, and the most closely related eupelycosaurs with hyoid bones are varanopids (e.g., Anderson and Reisz, 2004). The bones of the holotype of Gordodon kraineri that we identify as atlantal ribs are flat and strap-like, not round in cross section, as are other hyoids (for example in the varnopid Pyozia: Anderson and Reisz, 2004). They are, indeed, similar to already described eupelycosaur atlantal ribs (e.g., Romer and Price, 1940). Also, the Gordodon specimen is almost perfectly articulated, and even has sclerotic ring fragments preserved in the orbit. So, if these bones were hyoid elements in place, they should extend anteriorly between the lower jaws. As atlantal ribs, they are very close to being in place. Nevertheless, despite these arguments, identification of atlantal ribs (not hyoid elements) in the holotype of $G$. kraineri is tentative.

Cervical ribs: The atlantal ribs are short and thin. They are essentially flat, slightly wider proximally and distally, and narrower at mid-length (Figure 7). Both of these ribs are displaced in the posteroventral direction. The right atlantal rib is a thin, slightly curved bone that has been displaced ventrally so that its proximal end is just ventral to the posterior end of the quadrate. This rib is $34 \mathrm{~mm}$ long and has long and flat proximal and distal ends, but narrows to a slender shaft at about mid-length. The left atlantal rib is similar to the right rib in shape and size (it is $35 \mathrm{~mm}$ long). It is lying just ventral to the posterior part of the axis centrum and most of the cervical 3 centrum.

Cervical rib 2 is nearly in place and articulated, though it is missing its distal end. The tuberculum and capitulum are nearly at right angles to each other. The tuberculum is very short, wide and directly articulated to the transverse process. The capitulum is a longer, thin rod of bone with a blunt articular end that is in contact with the posterior end of intercentrum 1.
On the right side, cervical rib 3 is similar to 2 in lacking most of its shaft and having the tuberculum in contact with the transverse process. This rib is larger than rib 2, but of the same overall shape. The distal portion of its counterpart on the left side emerges from beneath centrum 3 to sweep posteriorly to a thin, blunt tip.

Cervical rib 4, however, is a much larger bone with a triangular, expanded distal end. At least 45 $\mathrm{mm}$ long, its proximal end is ventral to the anterior edge of cervical centrum 4.

The next visible rib, of cervical vertebra 5 , is much larger than cervical rib 4 (more than $50 \mathrm{~mm}$ long) and preserves a proximal end with two distinct heads. It has a broad ventral end that is a nearly triangular plate of bone with a slightly concave distal end.

Dorsal ribs: Rib 6, showing a curved rod-like structure, breaks from the pattern of the more anterior ribs, which are wider and flatter progressing down the vertebral column. Thus, it represents the first dorsal rib (Romer, 1956). Its ventral end is covered by the shoulder girdle, making its exact length impossible to determine. All subsequent ribs are of similar morphology, but their distal ends extend off the block.

The dorsal series ribs, particularly on the left side, are well preserved proximally, but none show their full length. The dorsal series ribs are much longer than the cervical ribs and more heavily constructed. Their shafts are rounder and thicker, and a shallow, anteromedial sulcus represents a moderately-developed costal groove.

Ribs 6,7 and 8 are dorsal ribs that are much longer than the preceding ribs. Rib 7 is the most complete, and it is at least $117 \mathrm{~mm}$ long. These ribs have long, flattened and curved shafts and (at least on 7) a well-separated tuberculum and capitulum proximally. Parts of two more ribs are associated with centra 9 and 10 . They are eroded and incomplete but appear similar to ribs 7 and 8 . Given their gentle proximal curvature, it seems unlikely that Gordodon was barrel chested, as was Edaphosaurus.

Pectoral girdle. Part of the right scapula and clavicle are preserved overlying the first dorsal ribs (Figures 2, 7). The preserved dorsal portion of the right clavicle is a thin flange of bone sutured laterally to the anterior edge of the right scapula. However, both the dorsal tip of the clavicle and the dorsal part of the scapular blade are broken and not present. The clavicle widens ventrally to form a broad, trapezoidal plate of bone with a concave medial edge. The portion of the scapula that is 
present is the body distal to the blade, minus the glenoid buttress. The expanded ventral portion of the clavicle overlaps and is sutured to the anterior edge of the scapula. In close contact with the ventral plate of the right clavicle is a piece of bone that we infer to be the ventral plate of the left clavicle, which has been displaced to lie immediately ventral to the right scapula-clavicle.

A portion of the left scapular blade is visible between the neural spines of the ninth and tenth vertebrae. Other than the rectangular shape of the dorsal end of the scapular blade, the visible portion is too small to allow additional morphological description.

Manual (?) phalanges. Overlapping the proximal third of the neural spines of dorsal vertebrae 10-12 is part of a digit of the manus(?), and another incomplete manus(?) digit is overlapped by the neural spine of dorsal 13 (Figure 7). Between dorsal neural spines 10 and 11 is a 33-mm long phalanx with a thicker proximal end (it bears a large flexor tubercle) and a smaller distal end. Between the ends, this bone is constricted, nearly round in cross section and slightly curved (concave toward the plantar surface). It is almost articulated distally to a 25-mm-long smaller but similar phalanx, which is articulated distally to a $15-\mathrm{mm}$-long curved ungual phalanx (claw) with a pointed tip that overlaps dorsal neural spine 12. Between dorsal neural spines 12 and 13, overlapped by 13 and between 13 and 14 are two distal phalanges of similar size to those just described but eroded. Given the relative lengths of the phalanges, their orientation with respect to the skeleton and the fact that only the anterior part of the Gordodon skeleton is preserved, these appear to be parts of digit I and II of the manus(?).

\section{Comparison to Other Eupelycosaurs}

Gordodon is clearly an edaphosaurid that is very different from the other named edaphosaurid genera. Glaucosaurus from the lower Permian of Texas is known only from a single small, incomplete and likely juvenile skull (Williston, 1915; Modesto, 1994). This skull has a short snout, essentially isodont marginal teeth that are laterally compressed, conical, pointed, and closely spaced and a prearticular that enters the lower jaw symphysis, features that readily distinguish it from Gordodon. However, the long maxilla and relatively deep suborbital bar of Glaucosaurus, previously considered unique to the genus (Modesto, 1994), can now be seen as features it shares with Gordodon.
Lupeosaurus is an edaphosaurid known from incomplete postcrania from the lower Permian of Texas (Romer, 1937; Romer and Price, 1940; Sumida, 1989). The lack of tubercles on the vertebral neural spines, which have a round cross section and shallow anterior and posterior furrows, readily distinguishes Lupeosaurus from Gordodon and the other edaphosaurids.

lanthasaurus is known from cranial, mandibular and diverse postcranial material from the Upper Pennsylvanian of Kansas and Colorado (Reisz and Berman, 1986; Modesto and Reisz, 1990b; Sumida and Berman, 1993; Mazierski and Reisz, 2010). Cranial material of lanthasaurus includes two dental morphologies of closely spaced teeth-an isodont dentition of curved and pointed teeth, and a dentition of long, peg-like teeth that is isodont except for an enlarged, caniniform tooth positioned relatively posteriorly. However, it is likely that the isodont dentition of curved and pointed teeth is not actually that of lanthasaurus, but was associated with it from intermingled remains of different taxa on the same bedding plane (Mazierski and Reisz, 2010). Nevertheless, either dentition is very different from that of Gordodon. Furthermore, the neural spines of lanthasaurus have subcircular cross sections, and eight or fewer relatively robust tubercles on each side, which are generally symmetrically arranged on either side-very different from the neural spines of Gordodon.

The archetypal edaphosaurid, Edaphosaurus, is well known from abundant cranial and postcranial material, primarily from the Upper Pennsylvanian-lower Permian of the western USA, and from less complete specimens from the eastern USA (e.g., Case, 1906a, 1906b, 1918; Romer and Price, 1940; Romer, 1952; Berman, 1979; Reisz, 1986; Modesto and Reisz, 1990a; Modesto, 1995). European records that may belong to this genus are less complete (e.g., Fritsch, 1895; Jaekel, 1910; Voigt et al., 2014). There are many differences between the skull and postcrania of Edaphosaurus and Gordodon listed in the diagnosis above. Salient points are the striking differences between the masticatory apparatuses and neural spine tubercles of the two genera.

The mandibular tooth-plate teeth of NMMNH P-70796 are smaller than those of Edaphosaurus. In E. novomexicanus, the mandibular tooth plate teeth vary in size, reaching $\sim 3 \mathrm{~mm}$ in diameter, larger than the diameter of the preserved marginal teeth (Modesto and Reisz, 1992, pers. obs.). In E. boanerges, the mandibular tooth plate teeth are $\sim 3$ $\mathrm{mm}$ in diameter (Modesto, 1995), and in E. pogo- 
nias they are $>2 \mathrm{~mm}$ in diameter (Romer and Price, 1940 , pl. 17). In both E. boanerges and E. pogonias, tooth diameter does not vary significantly across the toothplate.

The intercentra of NMMNH P-70796 are larger relative to the size of the centra than in other edaphosaurid species. They are more cylindrical and are contained within a deep embayment in the anteroventral centra. In other edaphosaurs (e.g., $E$. boanerges, E. cruciger, E. pogonias: Case, 1906a; Romer and Price, 1940) and in some other eupelycosaur species (e.g., Varanosaurus acutirostris and Ophiacodon: Reisz, 1986; Sumida, 1990), the intercentra are relatively smaller, more wedge shaped, and are accommodated by curving or angular beveling of both the anteroventral and posteroventral surfaces of the centra.

The vertebral centra of Gordodon appear to be considerably more gracile than those of other eupelycosaurs. Here, we quantify this observation. We thus compared the robustness of Gordodon centra to those of other edaphosaurids and to some other eupelycosaurs for which metric data are available (largely from Romer and Price, 1940, table 3).

The relationship of length to diameter of the centra defines their robustness. When the centra are considered as approximately cylindrical beams, these factors determine their resistance to bending under a load (e.g., Marks, 1951). We define robustness as the posterior height of the centrum (approximate diameter, $\mathrm{HC}$ ) divided by maximum length of the centrum (LC): robustness = post HC/LC (Table 2). Thus, higher numbers indicate a more robust centrum, and lower numbers indicate a more gracile centrum.

The axis, post-axial cervical and anterior dorsal centra were treated separately (Figure 13). Anterior dorsal was arbitrarily defined as vertebra 16 or vertebrae anterior to that position. The number of vertebrae measured is indicated as " $\mathrm{N}$ " on the plots and may refer to multiple vertebrae of one specimen and/or multiple specimens. Where multiple measurements were available, they were averaged.

The axis of Gordodon is more gracile than any of the other pelycosaurs sampled, although Dimetrodon natalis is a close second (Figure 13). The post-axial cervicals and anterior dorsals are, likewise, more gracile than those of the sampled eupelycosaurs with the single exception of one anterior dorsal of Edaphosaurus novomexicanus, which is approximately equal or very slightly more gracile. Other, less closely-related pelycosaurs (e.g., Ophiacodon, Varanosaurus) were spot checked, and all showed more robust centra than Gordodon, although these were not plotted. The quantitative study showed that, with very rare exceptions, the centra of Gordodon are substantially more gracile than those of other eupelycosaurs (Figure 13).

In the herbivorous edaphosaurids and caseids, the dorsal vertebrae are more elongate than the cervical vertebrae (Kemp, 1982). This is borne out, with a single exception (Edaphosaurus pogonias), in our analysis (Figure 13). In Gordodon, the cervical vertebrae are essentially identical in elongation to the dorsal vertebrae. Additionally, the axis is more elongate than the postaxial vertebrae (Figure 13).

Kemp (1982) notes that the centra of edaphosaurids and caseids lack a ventral keel, whereas the centra of Gordodon show a double keel (as do those of derived ophiacodontids: Benson, 2012). This adaptation probably functions to strengthen the centra, as they are otherwise more gracile and subject to bending than those of other eupelycosaurs (Figure 13; text above). Such a keel would act as the web of an I-beam does, strengthening the element against bending in the vertical plane with little addition of weight.

As shown above, the neural spine tubercles of NMMNH P-70796 are random (Poisson distribution, Figure 12) in their occurrence along the length of the neural spine and in their individual lengths and diameters (Normal distribution, Figures 10.2, $11.1,11.2)$. Additionally, there is no predictable relationship between the length and diameter of any individual tubercle, i.e., size does not predict shape (Figures 9.2, 10.1). We conclude from simple observation that the neural spine tubercles of other edaphosaurids (e.g., Edaphosaurus boanerges, E. cruciger, E. pogonias) are distributed with more regular (more ordered) spacing along the neural spines, frequently configured in opposing pairs, are of more uniform shape (length to diameter ratio), and tend to be larger and longer near the base of the neural spine (e.g., Case, 1906a; Romer and Price, 1940; Reisz, 1986).

In order to quantify this observation, we performed the same spatial distribution test that was used on the Gordodon neural spine tubercles on Edaphosaurus pogonias (Figure 12). The slope of the Gordodon curve fit line is $\sim 0.95$ (Figure 12.2, solid line), indicating a near-perfect Poisson distribution, whereas the slope of the $E$. pogonias curve fit is 0.38 (Figure 12.2, dashed line), indicating a well-ordered distribution. E. cruciger and E. boan- 


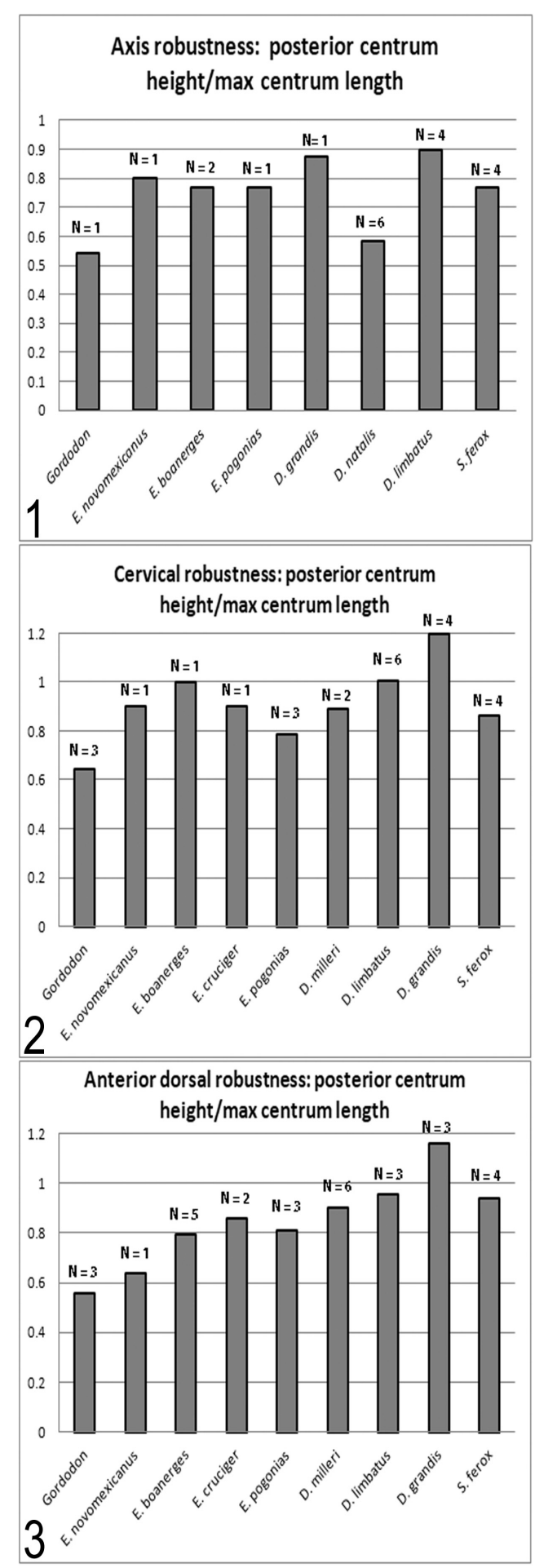

FIGURE 13. Comparison of the relative robustness of the axis (1), the post-axial cervicals (2), and the anterior dorsals (3) of Gordodon to that of several eupelycosaurs. The posterior height of the centrum is divided by its maximum length, so higher numbers indicate a relatively short, robust centrum and lower numbers indicate a relatively long, slender centrum. E. = Edaphosaurus, D. = Dimetrodon, $\mathrm{S}$. $=$ Sphenacodon . erges show intermediate levels of orderliness in their tubercle distributions; slightly less ordered than E. pogonias, but definitely not random, as in Gordodon. The E. pogonias data were measured from the skeletal restoration of Romer and Price (1940, figure 68), and were confirmed by observation of the mounted skeleton of Edaphosaurus on display at the FMNH.

In the relative lengths and curvature of the neural spines that make up the sail, Gordodon more closely resembles lanthasaurus than it does Edaphosaurus (Figure 14). Thus, the preserved portion of the sail of Gordodon indicates that its neural spines increase in height backward from the first cervical spine, so that the peak height of the sail is at about neural spine 16. In contrast, this peak is reached in Edaphosaurus around neural spine 12, whereas in lanthasaurus the peak is also at about neural spine 16. The sails of Edaphosaurus and lanthasaurus are of nearly even height from neural spine 8 backward, whereas in Gordodon the neural spines increase in length substantially until about neural spine 12 . Thus, the profiles of the sails of Edaphosaurus and lanthasaurus are much more nearly semicircular, whereas at the least the anterior portion of the sail of Gordodon has a steep slope (Figure 14). Whether or not other differences are present in the posterior part of the sail of Gordodon will, of course, have to await the discovery of more complete material.

\section{PHYLOGENETIC ANALYSIS}

Gordodon possesses a number of anatomical features that have not been reported in any other Paleozoic synapsid. It also unequivocally displays key characters of the Edaphosauridae, including: relatively small skull, reduced marginal dentition, ventrally displaced jaw articulation, and greatly elongated neural spines bearing lateral protuberances (Reisz, 1986). Mazierski and Reisz (2010) published the latest phylogenetic analysis focused on the Edaphosauridae, with the ingroup taxa represented by five species of Edaphosaurus (E. colohistion, E. novomexicanus, E. boanerges, $E$. cruciger and E. pogonias), lanthasaurus hardestiorum, Glaucosaurus megalops and Lupeosaurus kayi, with Mycterosaurus longiceps (Berman and Reisz, 1982), Ophiacodon mirus (Williston and Case, 1913) and Haptodus garnettensis (Laurin, 1993) as outgroup taxa. Here, we augment their analysis by adding the character states present in Gordodon (see Supplemental Material of character states). 


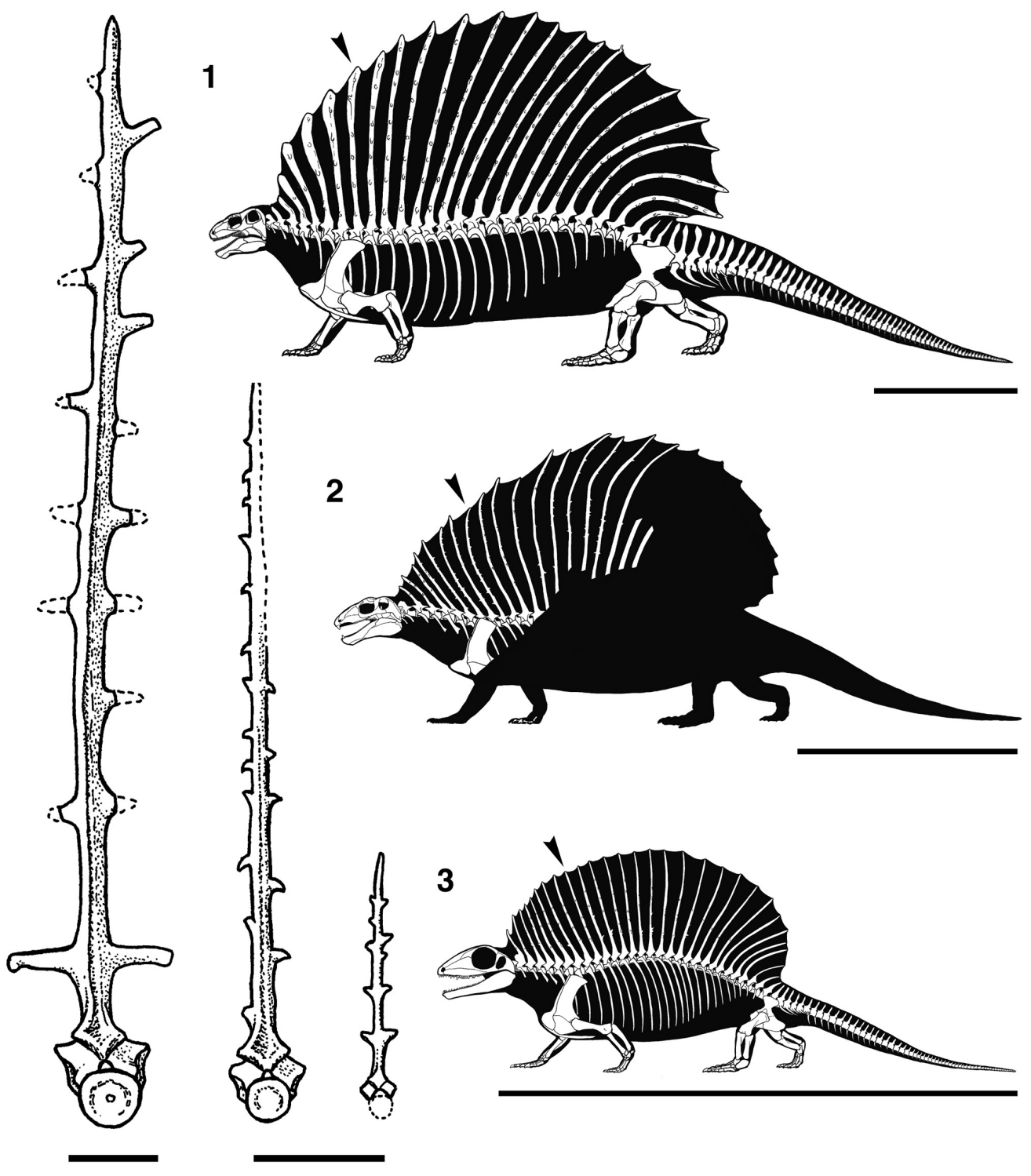

FIGURE 14. Comparison of edaphosaurid anterior dorsal vertebrae (in anterior view) and skeletal reconstructions. 1, AMNH 4060, Edaphosaurus cruciger (modified from Case, 1906a, plate 28). 2, NMMNH P-70796, Gordodon kraineri. 3, KUVP 69035 (vertebra)/ROM 37751 (skeleton), immature lanthasaurus hardestiorum (modified from Reisz and Berman, 1986, figure 2). Vertebra scale bars equal $5 \mathrm{~cm}$, skeletal reconstruction scale bars equal $0.5 \mathrm{~m}$.

Character states for Gordodon could be coded for 30 of the 39 characters in the study; data were unobtainable only for the palate (largely obscured in Gordodon) and parts of the postcrania. In three of the 39 characters, the features of Gordodon are intermediate between the states listed by Mazierski and Reisz in their character descriptions. These are: character 17 (skull length:dorsal vertebrae), character 18 (postorbital length:preorbital length) and character 22 (mandible height:length). In these instances, we replaced the characters of Mazierski and Reisz (2010) with comparable characters from Benson (2012) (see Supplemental Material for details).

We used the data matrix of Mazierski and Reisz (2010) and modified it by adding Gordodon. The data matrix was constructed in Mesquite 3.2 (Maddison and Maddison 2017), and multistate characters were unordered and unweighted. Phylogenetic Analysis Using Parsimony (PAUP)* 4.0a (build 158) (Swofford, 2002) was used to analyze the data using a branch-and-bound algorithm with DELTRAN optimization. Bootstrap values were generated in PAUP* with the branch-and-bound 
algorithm (1000 replicates). Bremer decay values were calculated by manually increasing the maximum tree length by 1 and recording which nodes collapsed when the analysis was recalculated.

The analysis resulted in three most parsimonious trees with a length of 54 , which were combined into a strict consensus tree (Figure 15.1). Compared to Mazierski and Reisz (2010), the inclusion of Gordodon strengthens the nodes at the base of the Edaphosauridae with lanthasaurus as the basalmost member of the family and Glaucosaurus as the sister taxon to a clade containing Gordodon, Lupeosaurus, and Edaphosaurus. However, relationships in the middle of the tree were not supported, with Gordodon, Lupeosaurus, E. colohistion and $E$. novomexicanus forming a polytomy with a clade of derived Edaphosaurus species.

Removal of one or both of the taxa for which no cranial material is known (Lupeosaurus and $E$. colohistion) helped resolve the middle of the tree (Figure 15.2). If E. colohistion is removed from the analysis, Gordodon nests as the sister taxon to a clade containing Lupeosaurus and Edaphosaurus. If Lupeosaurus is removed instead, Gordodon nests as the sister taxon to a clade containing $E$. colohistion + the remaining Edaphosaurus species. Identification of additional edaphosaurid postcranial characters or, ideally, the discovery of cranial material referable to the "headless edaphosaurs" may help clarify the relationships of these taxa.

Vermeij (1999) made the cogent observation that cladistic analysis is a kind of cluster analysis in which the character states are interdependent, so that the identification of a clade is influenced by the character states of other clades in the analysis. However, the evolutionary process of speciation should produce genetically distinct clades so that the genetics (and therefore character states) of separate clades should not be interdependent.

This is best seen by removing a taxon from a cladistic analysis, which will change the shape of the cladogram. Indeed, the edaphosaurid phylogeny presented here (Figure 15) changes shape when a taxon is removed, thus confirming Vermeij's observation. It is important, therefore, to regard the cladogram as a phylogenetic hypothesis, at most, one not consistent with Darwinian theory, pending development of a method of phylogenetic analysis consistent with the evolutionary process.

\section{MASS OF GORDODON}

Body mass calculations are an important and interesting, but problematic aspect of paleobiology. Numerous methods exist, and results vary widely between them (Hurlburt, 1999). Some methods based on living alligators use total body length (snout to tip of tail) (Dodson, 1975), or total body length and tail girth (Woodward et al., 1991). Additional methods use limb-bone dimensions, for example, femur circumference (bipeds) or humerus and femur circumferences (quadrupeds) (Anderson et al., 1985), or, in the case of ALLMASS programs (Hurlburt, 1999), the lengths, diameters and circumferences of multiple limb bones.

The best results were obtained by Hurlburt's (1999) Graphic Double Integration (GDI) method wherein a three-dimensional reconstruction of the animal was divided into segments whose volume could be easily calculated. The volumes of the segments were then reintegrated and multiplied by the specific gravity $(\sim 1)$ to find the total mass. GDI gave excellent results when used to calculate the mass of extant reptiles in which the calculated and measured masses could be compared.

Hurlburt (1999) found that the method of Romer and Price (1940), in which they used a halfscale clay model immersed in water to obtain an accurate volume, yielded results that were not as good as GDI, but were as good as, or better than, the other methods described above. The advantage of the Romer and Price results for our purposes is that we can scale Gordodon to Edaphosaurus based on the size of the dorsal vertebral centra, so that knowledge of the limb bone dimensions and/or total length, which are missing in Gordodon, is not required.

Here, we use the method of Romer and Price (1940, p. 9-10) by comparing Gordodon to the average of the calculated mass of four Edaphosaurus species (E. novomexicanus, E. boanerges, $E$. cruciger, E. pogonias) (Romer and Price, 1940, table 5). Using a scaling factor based on the square of the radius of the dorsal vertebral centra measured at the posterior surface, the (first approximation) mass of Gordodon is $34 \mathrm{~kg}$ ( 75 Ibs). Table 3 compares the mass of Gordodon to most of the species of Edaphosaurus and shows that it is a considerably smaller animal. Given that the holotype of Gordodon does not represent a juvenile individual (note, in particular, the evident fusion of sutures on the vertebrae and shoulder girdle), this means that its small size likely indicates 

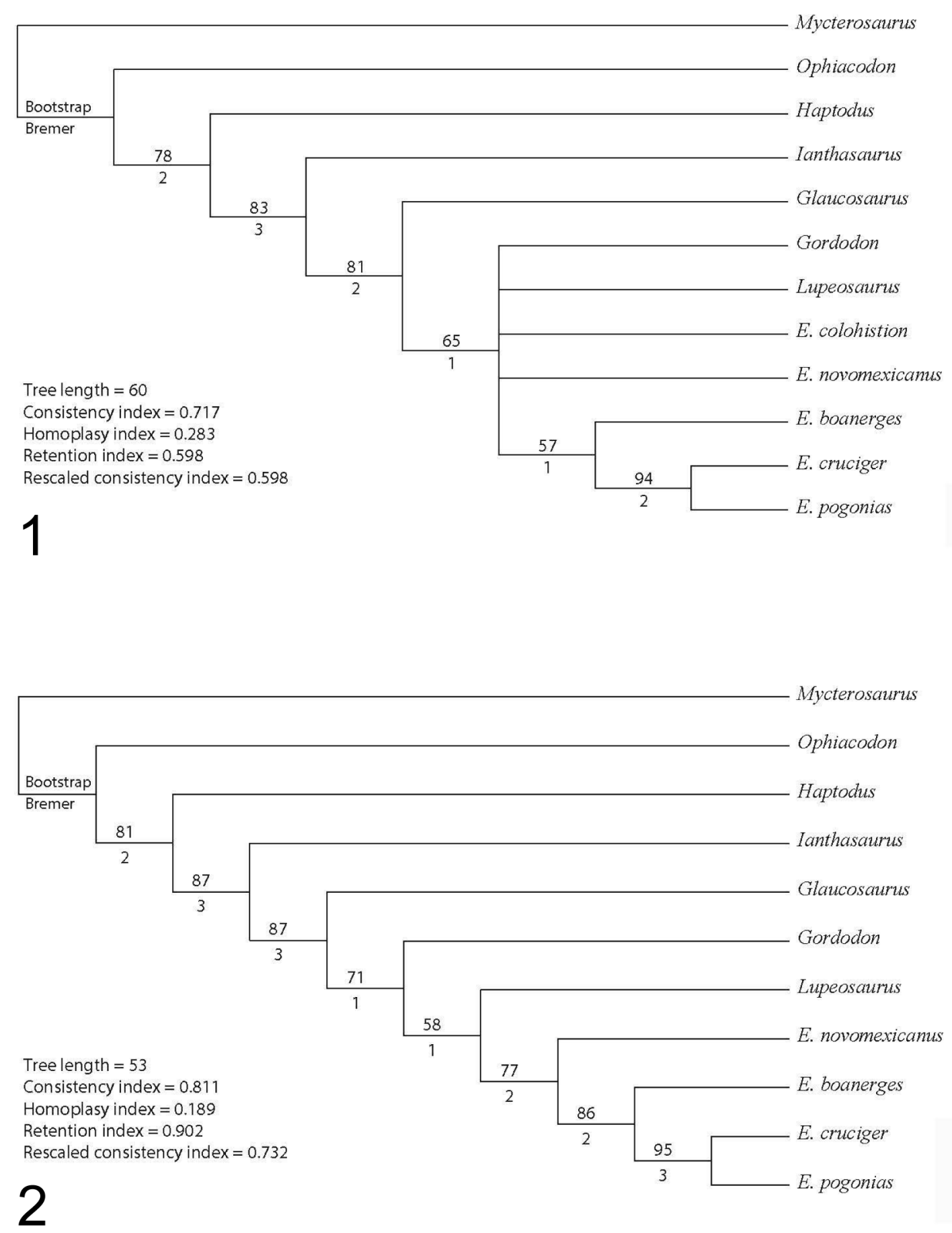

FIGURE 15. Hypothesis of edaphosaur phylogenetic relationships, including Gordodon kraineri. 1, Strict consensus tree. 2, Tree after removal of Edaphosaurus colohistion.

utilization of plant foods different from those utilized by the much larger Edaphosaurus.

\section{HERBIVOROUS ADAPTATIONS IN EDAPHOSAURIDS}

Only two of the well-known edaphosaurids were definitely herbivores-Edaphosaurus and 
TABLE 3. Calculated mass of some edaphosaurids. Gordodon, this study; all others Romer and Price (1940, table 5).

\begin{tabular}{lc}
\hline \multicolumn{1}{c}{ Taxon } & $\begin{array}{c}\text { Mass } \\
(\mathbf{k g})\end{array}$ \\
\hline Gordodon kraineri & 34 \\
Edaphosaurus novomexicanus & 63 \\
E. boanerges & 83 \\
E. cruciger & 166 \\
E. pogonias & 186 \\
\hline
\end{tabular}

Gordodon. Here, we compare and contrast the herbivorous adaptations of both genera.

\section{Herbivory of Gordodon}

Positing herbivory in an extinct tetrapod relies on identifying morphological features of the masticatory system (skull, jaws, dentition) that are correlates of herbivory. The tooth and the jaw morphology of Gordodon are, in many aspects, atypical of edaphosaurids. There are, however, some important similarities. These include a relatively small head and short snout (compared to sphenacodontids), a lateral temporal fenestra that is small relative to the orbit, the jaw joint offset below the level of the tooth row, a massive, deep lower jaw, and mandibular toothplates (Figure 16.1). Thus, the skull, jaws and teeth of Gordodon show numerous features that are indicative of herbivory (e.g., Hiiemae, 1967; Smith, 1993; King, 1996; Reisz and Sues, 2000; Hildebrand and Goslow, 2001; Elbroch, 2006).

The large incisors and small, peg-like marginal cheek teeth of Gordodon are for cropping vegetation. The vomerine teeth, mandibular tooth plate and (presumably) pterygoid teeth are suitable for crushing and grinding, though such teeth are a primitive feature and not, by themselves, indicative of herbivory. Gordodon has a diastema that allows the alternating engagement of the incisors and the cheek teeth for cropping, and the mandibular tooth plate and pterygoid teeth, for mastication. In some extant mammals, it also forms a passage whereby vegetation can be forced out into the cheeks for short-term storage during cropping and later brought back into the mouth for processing. The lack of large numbers of foramina in the premaxilla, maxilla or dentary of Gordodon as well as the fact that the lateral margins of its maxilla and dentary do not protrude to create a "lateral gap" to the cheek-tooth row argue against the presence of extra-oral tissues such as a beak, epidermal tooth covering or muscular cheek (cf. Galton, 1973; Nor- man and Weishampel, 1985; Morhardt, 2009). Nevertheless, food fragments cropped/chiseled by the incisors of Gordodon could have been accumulated and retained in the front of the mouth before being passed back to the mandibular and pterygoid teeth for grinding/pulping. In Gordodon, the unfused mandibular symphyses, though plesiomorphic for synapsids, are an important element of this as they allow independent movement of the mandibles with efficient transfer of dorsally oriented forces (Lieberman and Crompton, 2000).

The jaw joint of Gordodon is offset below the level of the tooth row so that it tends to bring the upper and lower teeth into occlusion simultaneously along the length of the tooth row (rather than progressing from back to front with a shearing action) and to increase the mechanical advantage of the jaws for more effective crushing and grinding. The poorly defined and loosely fitting jaw joint (Elbroch, 2006) of Gordodon has a small and spherical articular surface that allows easy anteroposterior motion of the mandible for the purpose of alternately engaging the incisors and the cheek teeth and toothplates. This adaptation also allows propalinal translation of the mandible during the power stroke for grinding vegetation.

The relatively small lateral temporal fenestra (i.e., compared to the orbit) and a long squamosal-jugal (zygomatic) bar of Gordodon also are indicative of herbivory. In mammals, these characters accommodate the relatively small temporalis and the large masseter and pterygoidus muscles that are typical of herbivores. In eupelycosaurs, these features accommodate the adductor muscles (e.g., Barghusen, 1973; Kemp, 1982). However, the ventral border of the lateral temporal fenestra of Gordodon is not bowed dorsally, as it is in Edaphosaurus (King, 1996). Indeed, in Gordodon, a long, low, robust coronoid eminence of the mandible increased the insertion area of the large adductor muscles.

\section{Jaw Musculature and Gape of Gordodon}

We can also assess muzzle shape, jaw gape and origin-insertion ratio (defined below) of the jaw muscles of Gordodon as indicators of diet and feeding style (Figure 17). Herring and Herring (1974) successfully used the "quantifunctional approach" of Gould (1970) to predict the maximum gape of numerous $(\mathrm{N}=48)$ extant mammals by analyzing the superficial masseter muscle. In mammals, the superficial masseter originates near the posteroventral border of the orbit and inserts on the lateral posteroventral apex of the mandible. 
1

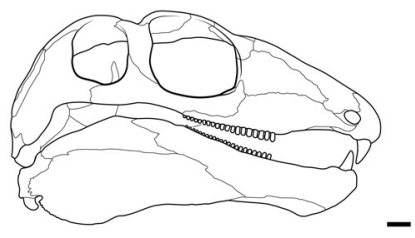

4

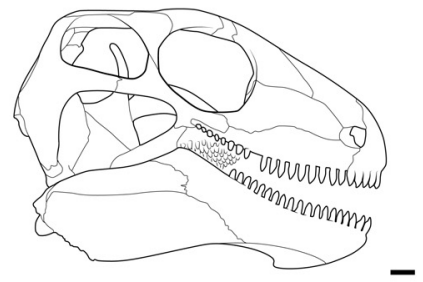

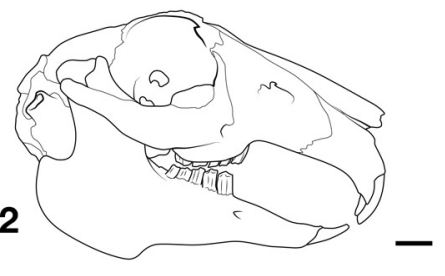

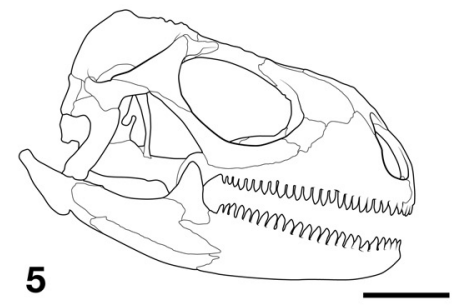

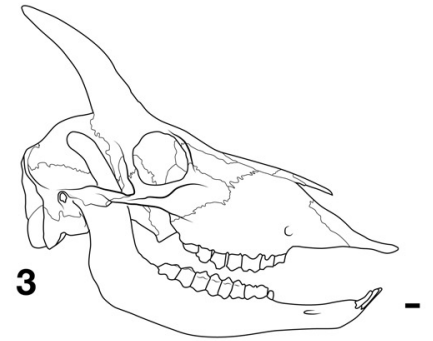

6

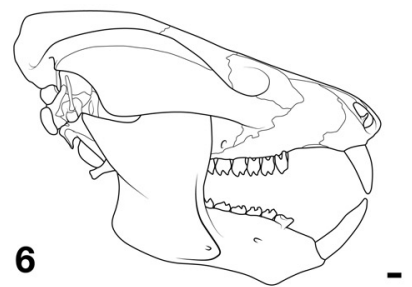

FIGURE 16. Comparison of skulls. 1, Gordodon kraineri. 2, Domestic rabbit, Oryctolagus cuniculus (after Farag et al., 2012, figure 4). 3, The artiodactyl Oreamos americanus, Rocky Mountain goat (after Gilbert, 1990, p. 223). 4, Edaphosaurus boanerges (after Modesto, 1995, figure 2). 5, Green iguana, Iguana iguana (after Porter and Witmer 2015, file S1). 6, The tritylodontid Kayentatherium wellesi (after Sues, 1986, figure 1). Scales equal $1 \mathrm{~cm}$.

In Gordodon, rugose muscle scars are located at the sites that would be expected to represent the origin and insertion of a muscle analogous to the superficial masseter of mammals. Specifically, a circular, rugose boss is located on the jugal near the posteroventral orbit border (origin), and an oval rugosity is seen on the lateral posteroventral apex of the angular (insertion) (Figure 17.1). A muscle connecting these two points would be positioned so as to assist the pterygoideus in propalinal motion of the jaw for grinding vegetation and for the engagement of the incisors for cropping. For purposes of this analysis, we assume that the postulated muscle was present in Gordodon and call it the superficial adductor.

The length of the superficial adductor in NMMNH P-70796 (by Pythagorean theorem) is $6.69 \mathrm{~cm}$ with the jaw closed (I in Figure 17). Using a maximum muscle stretch factor of 1.35 , the muscle could extend to $9 \mathrm{~cm}$ length at maximum gape ( $L$ in Figure 17.2) (Herring and Herring, 1974, found 1.3 to 1.4 to be the maximum stretch factor for masticatory muscles without damage). Then, solving trigonometrically for the maximum gape angle, we find that $\theta=65^{\circ}$ (Figure 17.2).

Herring and Herring (1974) found that the "origin-insertion ratio," i.e., the distance between the jaw joint and the muscle origin (a in Figure 17.2) divided by the distance between the jaw joint and the muscle insertion ( $b$ in Figure 17.2) is a good predictor of diet in the studied animals. In carnivores, the origin-insertion ratio varies from 2.4 to 3.4 , in insectivores it is 1.5 to 2.0 , primates (excluding lemurs) are generally around 1.0 and artiodactyls and perissodactyls vary from 0.9 to 1.9. The origin-insertion ratio of NMMNH P-70796 is 1.6.

Of the animals studied by Herring and Herring (1974), Gordodon, with an origin-insertion ratio of 1.6 and a maximum gape of $65^{\circ}$, is most dissimilar to the Carnivora and allies best with the Insectivora, Artiodactyla and Perissodactyla. It is essentially identical in these parameters to Oreamnos americanus, the Rocky Mountain goat (Figure 16.3) (origin-insertion ratio $=1.59, \theta=65^{\circ}-75^{\circ}$ ), which is known to be a browser (Prothero and Foss, 2007; Johnson, 2008).

Thus, with the proviso that we have correctly identified the origin and insertion points of a superficial adductor muscle, we conclude that the gape and origin-insertion ratio of Gordodon constitute further evidence of its herbivorous lifestyle, and, together with its narrow muzzle, show that it was a selective browser.

\section{Edaphosaurus as a High-fiber Herbivore}

Among edaphosaurids, Edaphosaurus (Figure 16.4) is perceived of as an obligate high-fiber herbivore (e.g., Kemp, 1982; Modesto, 1995; Hotton et al., 1997; Sues and Reisz, 1998; Reisz and Sues, 2000). It has a short skull, large temporal 

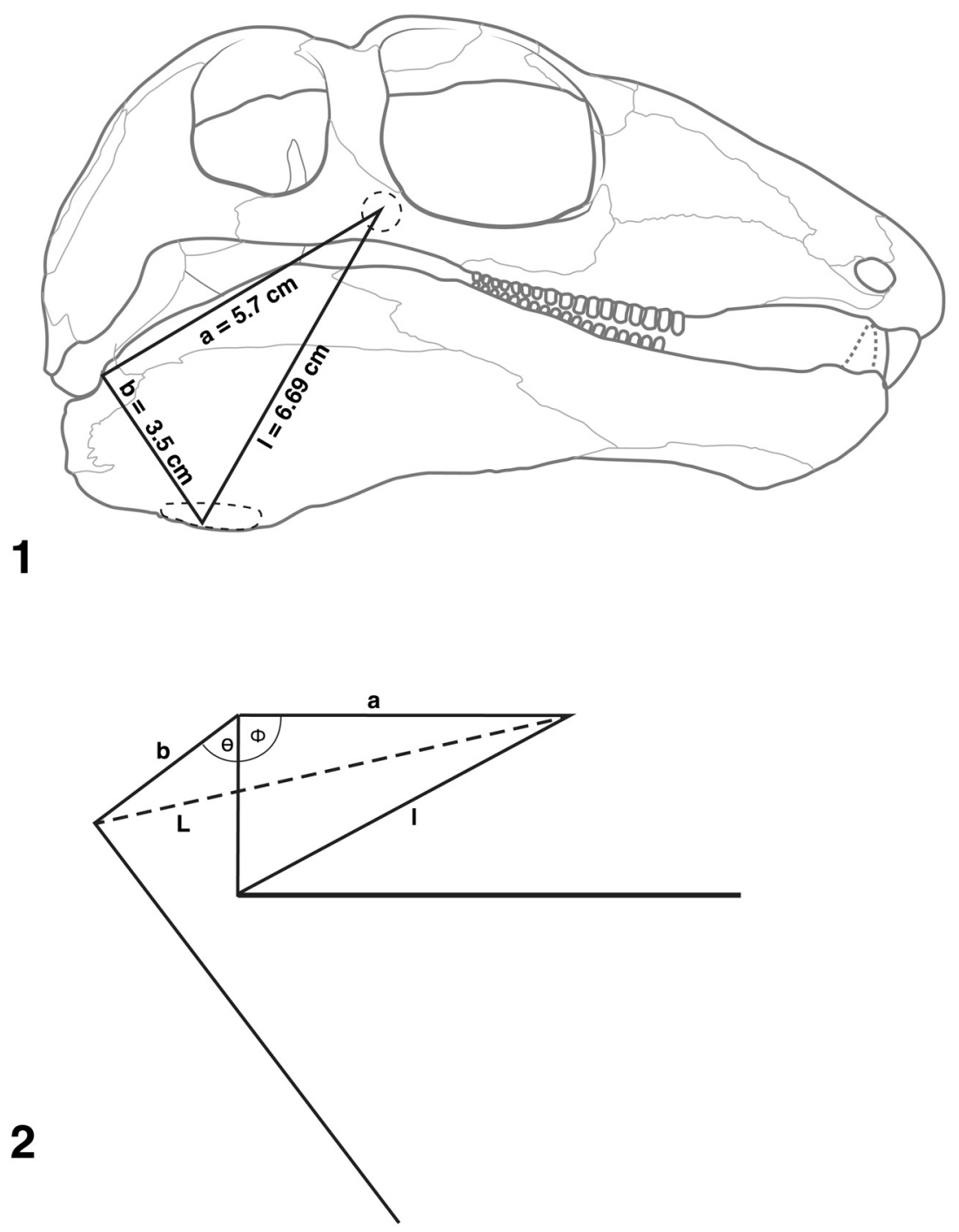

FIGURE 17. Maximum gape and origin-insertion ratio. Quantifunctional model of the proposed superficial adductor muscle of Gordodon originating at a circular, rugose boss on the jugal and inserting on an oval rugosity on the lateral posteroventral apex of the angular. 1, Model superimposed on the skull drawing. 2, Line diagram of the model after Herring and Herring (1974) in which the bold line represents the jaw closed (gape = zero degrees). Labels a, b, and I are as in 1, above: $a=$ distance from jaw joint to muscle origin; $b=$ distance from jaw joint to muscle insertion; $I=$ the action line of the muscle and (by Pythagorean theorem) its length with the jaws closed $(6.69 \mathrm{~cm}) ; \mathrm{L}=$ action line and length of muscle with jaws open; $\phi=$ angle between $a$ and $b$ with jaws closed $\left(\sim 90^{\circ}\right) ; \theta=$ angle subtended by jaws when wide open, i.e., the maximum gape.

fenestra and marginal teeth that are closely spaced, isodont, and consist of small short pegs in a relatively short tooth row. The palate has tooth plates that contact lingual tooth plates on the mandible of the lower jaw. The occiput is vertical, and the ventral border of the temporal fenestra is arched upward. The robust lower jaw has a large coronoid region (coronoid eminence). The jaw articulation is below the level of the tooth row, and, at the articulation, the articular facet is longer than the quadrate facet.

These features supported strong adductor muscles, and the main jaw-closing muscle in Edaphosaurus was the external adductor muscle (Kemp, 1982). The insertion for the pterygoideus is large on the angular and articular regions of the lower jaw. The result was that chomping with a limited amount of fore-aft movement of the jaw took 
place. Marginal teeth tore vegetation, and the palatal teeth pulped/crushed it.

The marginal cheek teeth of Edaphosaurus are slightly swollen with laterally compressed and finely serrated tips. Each tooth has an occlusal plane oblique to the long axis of the tooth (Modesto, 1995). The maxillary teeth are increasingly laterally directed on the maxillary tooth row, and the opposing dentary teeth are increasingly medially directed. Wear on the teeth indicates some retraction of the lower jaw at occlusion (Hotton et al., 1997).

In terms of a modern analogue, the living Iguana (Figure 16.5) has some of the key features of the masticatory system seen in Edaphosaurus. Most living iguanas are folivores that efficiently process foliage and stems (e.g., Hotton, 1955; Iverson, 1982; Troyer, 1984). These lizards consume large amounts of mature leaves, which are a high fiber and relatively low nutrient food source when compared to immature leaves and some other plant tissues, such as fruits and flowers. Iguanas simply shear the plant matter with their tooth row. Thus, their marginal teeth, which are laterally compressed, sharply cuspate and plate-like, function in shearing only (Hotton, 1955; Montanucci, 1968). However, unlike Edaphosaurus, Iguana lacks tooth plates to process the vegetation, and often ingests leaves whole, with no processing (Cooper and Vitt, 2003). Iguanas have valves that partition the colon to slow the passage of food to permit more time for the intestinal flora needed to degrade cellulose (Iverson, 1982; Troyer, 1984; Cooper and Vitt, 2002). Edaphosaurus has a barrel-shaped abdomen that has been seen to indicate a larger/longer digestive system to process cellulose (e.g., Reisz and Sues, 2000).

\section{Gordodon as a Specialized Herbivore}

Functional morphologists divide food handling by a tetrapod herbivore (the masticatory sequence of Schwartz et al., 1989, among others) into three phases: (1) ingestion, which is passage of food into the jaws or mouth cavity; (2) intraoral transport, which is movement of the food through the oropharyngeal chamber; and (3) deglutition or swallowing, whereby the food mass (bolus) is transferred from the pharynx to the esophagus (cf. Bramble and Wake, 1985). In a comparison of the masticatory apparatus of Gordodon and Edaphosaurus, it is clear that food handling by Gordodon differed significantly from Edaphosaurus in ingestion and oral transport. Gordodon evidently chiseled food with the large incisors, as do some modern rodents and rabbits. This would have placed food fragments in the diastema region until the tongue moved them back to the tooth plates to be broken down (masticated). However, unlike other tetrapod herbivores with a diastema, Gordodon did not have a cheek tooth dentition that did extensive work in mastication. In contrast, Edaphosaurus used its closely packed, isodont dentition (particularly the anterior teeth) to crop/tear vegetation that was passed directly into the oral cavity. The tooth plates then masticated (crushed by fore-aft motion and occlusion of the lower jaw) the vegetation to produce the bolus to be swallowed.

What distinguishes Gordodon from other edaphosaurids is its chisel-like incisors and long diastema. The diastema facilitates ingestion of small pieces of food, enabling the processing of these small pieces to take place in the anterior end of the mouth. In the tetrapod fossil record, a dentary diastema is known for some cynodonts (notably tritylodontids: Figure 16.6), mammals (especially multituberculates, rodents, lagomorphs and some artiodactyls: Figure 16.2, 16.3) and herbivorous dinosaurs (ceratopsians and iguanodontians) (Kemp, 2005; Kubota and Kobayashi, 2009). The oldest previously known herbivorous tetrapod with an unequivocal diastema was a cynodont (Figure 16.6) of Late Triassic age, $205 \mathrm{Ma}$ (Abdala and Gaetano, 2018). Gordodon extends the presence of a diastema in a tetrapod herbivore back to the beginning of the Permian, about 95 million years.

Among extant herbivores, some extant rodents, rabbits and artiodactyls (Figure 16) show a comparable dental apparatus, though they are much more specialized than Gordodon, having hypselodont incisors and/or hypsodont cheek teeth (premolars and molars) that functioned in grinding their plant food. In some rodents and rabbits, plant items are chiseled (gnawed) by the incisors to break it up into small particles that are not automatically passed to the oral cavity (e.g., Hiiemae, 1967; Hiiemae and Ardran, 1968; Hiiemae and Houston, 1971; Popowics and Herring, 2006). A complete separation of incision and mastication is achieved, as the incisors and molars can be occluded, but not simultaneously. To occlude, a forward or backward movement of the lower jaw is necessary.

In living ungulates (some artiodactyls and perissodactyls), narrow muzzles and incisor rows are characteristic of browsers and are also thought to facilitate selective cropping of vegetation (e.g., Janis and Ehrhardt, 1988; Pérez-Barbería and Gordon, 1999). The narrow muzzle and specialized 
dentition of Gordodon probably indicates a more selective browsing style than that of Edaphosaurus, with its wider snout and isodont marginal dentition. The possibility that Gordodon, like some extant mammals with a large diastema, had mobile lips and a protrusible tongue can be suggested, but is simply speculation without clear osteological evidence.

In general, plant materials high in cellulose add bulk (fiber) to a herbivore's diet but are of relatively low nutritional value. This forces the herbivore to intake large volumes of such plant material to meet nutritional requirements, and can also require increased food processing (Popowics and Herring, 2006). One strategy around this is to become a more selective feeder on low fiber plant materials with higher nutrient value. This was the likely purpose of the masticatory apparatus of Gordodon.

The earliest high-fiber herbivores among tetrapods have trunks that are barrel-shaped (Edaphosaurus) or elongate (diadectomorphs), which imply the slowing of passage of plant matter through the digestive system to promote the fermentation of cellulose (Hotton et al., 1997; Reisz and Sues, 2000). This is readily seen in Edaphosaurus, in which the ribs are markedly curved to form a barrel-shaped abdomen (Figure 14). The preserved incomplete ribs of Gordodon indicate no such marked curvature, and it appears to have had a more narrow, "slab-sided" abdomen like a sphenacodontid eupelycosaur. However, the posterior part of the skeleton of Gordodon is not known, so it may have had an elongate trunk like a diadectomorph. On the other hand, if Gordodon engaged in selective herbivory, it may not have needed much cellulolysis because it fed on low fiber vegetation (plant fructifications) and reduced its food to smaller particles during ingestion. Clearly, interpreting Gordodon as a selective browser on high nutrient, low fiber plant materials seems well supported by its cranio-dental anatomy (Figure 18).

\section{EDAPHOSAURID EVOLUTION AND EARLY TETRAPOD HERBIVORY}

The oldest herbivorous tetrapods are of Late Pennsylvanian age. As noted earlier, these are diadectomorphs, bolosaurids, edaphosaurids and caseasaurs. The herbivorous edaphosaurids (i.e., genus Edaphosaurus) are considered to have the oldest Pennsylvanian records of early tetrapod herbivores. Here, we begin by rigorously establishing the temporal (stratigraphic) ranges of the edapho- saurid genera (Figure 19). Within that framework, we discuss how Gordodon changes current perception of the evolution of herbivory in the Edaphosauridae.

The framework established here is based on edaphosaurid body fossils. The fossil footprints of eupelycosaurs are generally assigned to the ichnogenus Dimetropus, which has a stratigraphic range of Early Pennsylvanian (Bashkirian) through early Permian (Kungurian) (Voigt and Ganzelewski, 2010; Voigt and Lucas, 2018). Some of these footprints may have been made by edaphosaurids, but given the overall homeomorphy of most eupelycosaur feet (cf. Romer and Price, 1940; Reisz, 1986), it is impossible to associate any Dimetropus footprints with edaphosaurids to the exclusion of other eupelycosaurs (Voigt, 2005; Lucas et al., 2016).

\section{Temporal Range of lanthasaurus}

lanthasaurus is known from two localities in the USA: the Garnett quarry in Kansas and a locality near Howard in Colorado. The Garnett quarry is in the Rock Lake Shale Member of the Stanton Formation, a stratigraphic unit well constrained by fusulinid and conodont biostratigraphy to a late Missourian age (e.g., Heckel et al., 2007). The Howard locality is in the lower part of the Sangre de Cristo Formation and has been assigned a Missourian age (Vaughn, 1969a, 1972; Sumida and Berman, 1993), although there are no direct marine biostratigraphic constraints on its age. However, a Missourian age assignment can be defended by noting that the only other record of lanthasaurus, in Kansas, is Missourian. Thus, we assign lanthasaurus a late Missourian age, so it is the oldest known edaphosaurid.

\section{Temporal Range of Glaucosaurus, Gordodon and Lupeosaurus}

Glaucosaurus is known from a single skull from the Waggoner Ranch Formation (of Hentz, 1988, formerly referred to as the Clyde Formation) of Texas. This formation is of Mitchellcreekian age, which is early Leonardian/close to the Artinskian/ Kungurian boundary (Lucas, 2018). As discussed above, Gordodon is known from a single locality in New Mexico of earliest Wolfcampian age (Figure 19).

Lupeosaurus records are from the Moran, Putnam and Admiral formations of Texas (Romer and Price, 1940; Sumida, 1989), which is the Archer City Formation of Hentz (1988), as redefined by Lucas (2006). These are records of late Coyotean-early Seymouran age, which is middle- 


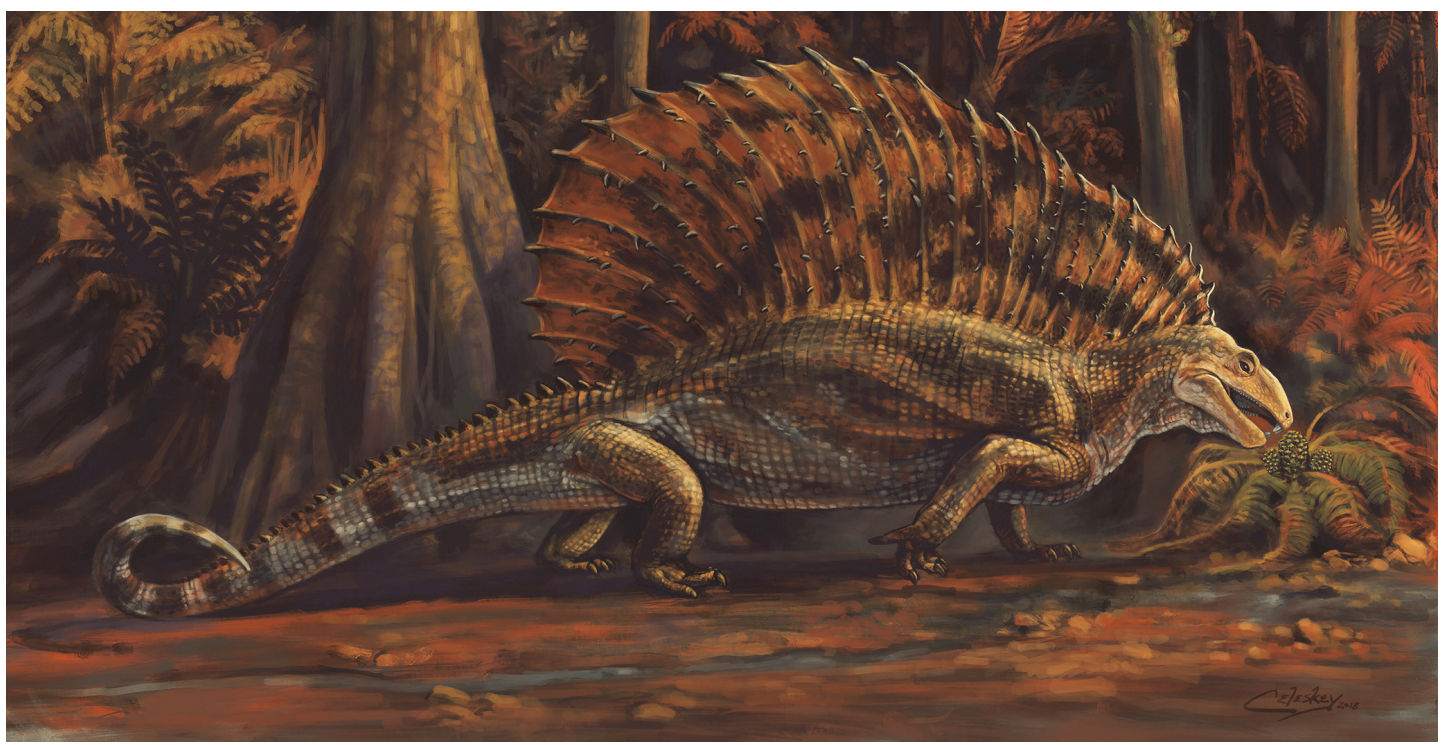

FIGURE 18. Life restoration of Gordodon kraineri.

late Wolfcampian/Sakmarian-early Artinskian (Figure 19).

\section{Temporal Range of Edaphosaurus}

The oldest North American records of Edaphosaurus are of E. novomexicanus from the Upper Pennsylvanian interval of the $\mathrm{El}$ Cobre Canyon Formation in New Mexico (Vaughn, 1963; Lucas et al., 2010), and E. colohistion from the upper part of the Pittsburgh Formation (Monongahela Group) in West Virginia (Berman, 1979). The New Mexican record lacks direct marine biostratigraphic dating, but is associated with palynomorphs, megafossil plants and other tetrapod taxa (Desmatodon, Limnoscelis) considered to be Late Pennsylvanian, most likely Virgilian, based on the megafossil plants (DiMichele et al., 2010; Lucas et al., 2010; Utting and Lucas, 2010). Therefore, we tentatively consider this record of Edaphosaurus as Virgilian.

The record of Edaphosaurus in the Pittsburgh Formation of West Virginia cannot be older than Virgilian, as the Ames Limestone of the underlying Conemaugh Group yields an early Virgilian (= early Gzhelian) conodont assemblage (Heckel et al., 2011). Indeed, the Pittsburgh Formation has long been considered Virgilian (e.g., Barlow, 1979; Edmunds et al. 1999), though there are no direct correlations of the Monongahela Group strata based on marine biostratigraphy. The age of the overlying Dunkard Group is most likely early Permian (e.g., Lucas, 2013a; Schneider et al., 2013), though some still consider the lowermost Dunkard strata to be Late Pennsylvanian (e.g., Tibert et al., 2013). Berman (1979) considered the Pittsburgh
Formation Edaphosaurus to be early Permian, because its relatively large size only fits perceived evolutionary trends in Edaphosaurus if E. colohistion is of early Permian age (also see Lund et al., 1979). However, given the ages assigned to the overlying Dunkard Group strata, it seems that the conventional age of late Virgilian assigned to the Pittsburgh Formation is most defensible, so we tentatively regard E. colohistion as of late Virgilian age.

Another Pennsylvanian record of Edaphosaurus is that of E.? mirabilis from Kounova in the Czech Republic (Fritsch, 1895). This locality has long been regarded as late Stephanian (Gzhelian/ Virgilian) based on macrofossil plant biostratigraphy (e.g., Štamberg and Zajíc, 2008). Opluštil et al. (2016) recently published a $206 \mathrm{~Pb} / 238 \mathrm{U}$ age of 301.5 Ma from a tonstein in the Kounonva coal, which indicates a middle Gzhelian age (Figure 19). However, within biostratigraphic resolution it is not possible to say which of the three Pennsylvanian records of Edaphosaurus is the oldest-New Mexico, West Virginia or the Czech Republic.

We should note here that Peabody's (1957) species Edaphosaurus ecordi from the late Missourian Garnett Quarry was removed from Edaphosaurus by Reisz et al. (1982), who coined a new genus name, Xyrospondylus, for it. This taxon, known from a single vertebra, is of problematic phylogenetic placement, either not included (Reisz, 1986) or included (Spindler, 2015) in the Edaphosauridae. Given its incomplete and problematic status, we do not include it in our analysis. 


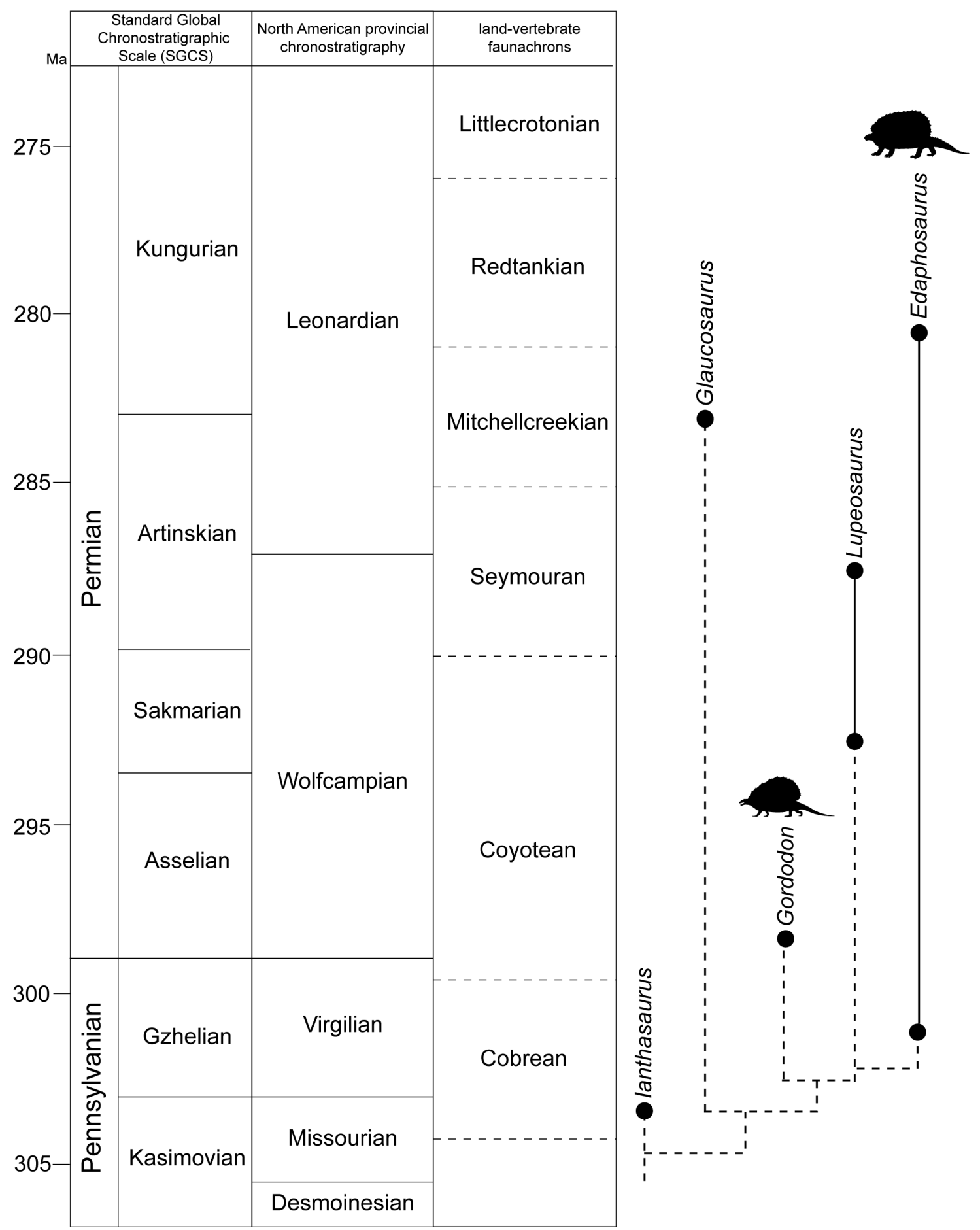

FIGURE 19. Time calibrated phylogeny of the Edaphosauridae. Numerical ages and their calibration to the standard global chronostratigraphic scale are from Schmitz and Davydov (2012), Ogg et al. (2016) and Ramezani and Bowring (2018). Cross correlation of the SGCS to the North American chronostratigraphic scale and the land-vertebrate faunachrons is based on Barrick et al. (2004), Wardlaw (2005), Heckel et al. (2007), Vachard et al. (2015) and Lucas (2006, 2017, 2018). 
Another potentially Pennsylvanian record of Edaphosaurus is of E. raymondi from the Pittsburgh red shale of the Conemaugh Group in Pennsylvania (Case, 1908). Modesto and Reisz (1990a) re-evaluted this taxon, identifying it as an indeterminate edaphosaurid. This is a Virgilian record.

The type material of Edaphosaurus novomexicanus is from the upper part of the El Cobre Canyon Formation near Arroyo del Agua, New Mexico (Williston and Case, 1913; Lucas et al., 2005), and this is a record of middle Coyotean age, which is early Wolfcampian/Asselian. Texas records of Edaphosaurus are from the Archer City through Lueders formations of the Wichita Group and from the Arroyo Formation of the Clear Fork Group (Hook, 1989; Lucas, 2017, 2018). This is a temporal range of early Seymouran to early Redtankian, which is late Wolfcampian-early Leonardian/early Artinskian-middle Kungurian (Figure 19). Brocklehurst et al. (2013) showed the range of Edaphosauridae extending to the end of the Kungurian, but the actual stratigraphically highest Edaphosaurus record is stratigraphically low in the Arroyo Formation (Olson and Mead 1982; Olson, 1989; Lucas, 2017), which is of middle Kungurian age (Figure 19).

In Europe there are two other records of Edaphosaurus. Edaphosaurus? credneri is based on a partial skeleton from the Niederhässlich interval of the Rotliegend in the Döhlen basin of Germany (Jaekel, 1910). This horizon is clearly Permian and has been correlated to the Sakmarian based on plant, insect and amphibian biostratigraphy and associated radioisotopic ages of $\sim 291 \mathrm{Ma}$ (e.g., Roscher and Schneider, 2006; Schneider and Werneburg, 2012).

Voigt et al. (2014) recently illustrated what appears to us to be a partial skeleton of Edaphosaurus from the Remigiusberg Formation in the Saar-Nahe basin of Germany. Old and imprecise radioisotopic ages of volcanic ashes in the Remigiusberg Formation and adjacent units indicate it is about $300 \pm 3 \mathrm{Ma}$. Thus, it is very close in age to the Carboniferous-Permian boundary (Figure 18). It has been assigned a latest Carboniferous age (Fröbisch et al., 2011), earliest Permian age (Rosscher and Schneider, 2006) or stated to be at the Carboniferous-Permian transition (Voigt et al., 2014).

\section{Evolution of Edaphosaurid Herbivory}

The analysis of age data presented above, summarized in Figure 19, indicates a total range of late Kasimovian (late Missourian) to middle Kun- gurian (late Leonardian) for the Edaphosauridae, or about 23 million years (280-303 Ma). What is striking is how low edaphosaurid diversity is during that lengthy time interval-only five genera, two herbivorous. In many later herbivorous tetrapod clades, diversity is much higher during a comparable interval. For example, about 30 genera of hadrosaurid dinosaurs are known during 23 million years of Late Cretaceous time (Horner et al., 2004), and among camelid artiodactyls, a similar 30 genera are known from about 25 million years of late Cenozoic time (Honey et al., 1998). In the Karoo basin of South Africa, there are 15 genera of dicynodontid therapsids during $\sim 13$ million years of middle-late Permian time (Smith et al., 2012).

It could be argued that this low edaphosaurid diversity is real, reflecting a modest diversification of herbivorous tetrapods during a very early experiment in herbivory. Furthermore, less fossiliferous rock volume and less collecting may account for at least part of the difference between edaphosaurid diversity and that of later herbivorous tetrapod clades. However, the relatively old record of a specialized herbivore, Gordodon, suggests that many edaphosaurid taxa are not known, and that their apparent diversity is thus incomplete. Furthermore, Gordodon indicates a marked increase in the disparity of edpahosaurids, as it represents a previously unknown ecological feeding type.

In the evolution of tetrapod herbivory, it is generally agreed that a carnivorous (or insectivorous) phase was followed by omnivory, then low-fiber herbivory and finally high-fiber herbivory. Thus, the longstanding understanding of the evolution of herbivory in edaphosaurids identifies lanthasaurus as a carnivore/omnivore (Mazierski and Reisz, 2010), Glaucosaurus as an omnivore (Modesto, 1994) and only Edaphosaurus as an obligate herbivore (Modesto, 1994; Reisz and Sues, 2000). However, based on the phylogenetic hypothesis in Figure 15.2, we can infer that Lupeosaurus was also herbivorous, because it is in between Gordodon and Edaphosaurus (i.e., it is more parsimonious to infer that herbivory evolved once in Edaphosauridae, presumably in the ancestor of Gordodon, Lupeosaurus and Edaphosaurus, than to infer that herbivory evolved twice in the clade). Also, as Hotton et al. (1997) noted, low fiber herbivory can also be an end member in evolution, and Gordodon may well represent that. Nevertheless, without direct evidence from gut contents or coprolites, determining the precise diet of Gordodon is impossible.

The discovery of Gordodon reveals that the evolution of edaphosaurid herbivory followed at 
least two paths: a generalized browser on highfiber plant foods (Edaphosaurus), and (2) a more specialized browser, one who likely consumed at least some higher nutrient, low-fiber plant foods (Gordodon) (Figure 18). The Edaphosaurus path first appeared during the Late Pennsylvanian, about $302 \mathrm{Ma}$, whereas the Gordodon path appeared at approximately the PennsylvanianPermian boundary, at about 299 Ma (Figure 19). Both plausibly evolved from an omnivorous precursor analogous to lanthasaurus. But, the appearance of such different feeding methods very early in edaphosaurid evolution likely indicates that there is an untapped diversity of herbivorous edaphosaurids awaiting discovery.

\section{ACKNOWLEDGMENTS}

We are grateful to $E$. Schuth for discovering the type specimen of Gordodon kraineri and to him and $L$. Soreghan for reporting it to us. The Roads Department of Otero County, New Mexico, through the good offices of W. Moore, made collection of the fossil possible. A. Cantrell and T. Suazo played a major role in collecting the fossil. Collection research by Lucas at the Field Museum of Natural History was facilitated by W. Simpson and A. Stroup. S. Modesto provided helpful comments on an earlier version of the manuscript. The comments of three anonymous reviewers and the style editor improved the content and clarity of the manuscript and figures.

\section{REFERENCES}

Abdala, F. and Gaetano, L.C. 2018. The Late Triassic record of cynodonts: Time of innovation in the mammalian lineage, p. 407-445. In Tanner, L.H. (ed.), The Late Triassic World. Springer Topics in Geobiology, 46. Springer Verlag, Berlin. https://doi.org/10.1007/978-3-319-680095_11

Anderson, J.F., Hall-Martin, A., and Russell, D.A. 1985. Long-bone circumference and weight in mammals, birds and dinosaurs. Journal of Zoology London A, 207:53-61. https://doi.org/ 10.1111/j.1469-7998.1985.tb04915.x

Anderson, J.S. and Reisz, R.R. 2004. Pyozia mesenensis, a new, small varanopid (Synapsida, Eupelycosauria) from Russia: "Pelycosaur" diversity in the middle Permian. Journal of Vertebrate Paleontology, 24:173-179. https://doi.org/10.1671/1940-13

Barghusen, H.R. 1973. The adductor jaw musculature of Dimetrodon (Reptilia, Pelycosauria). Journal of Paleontology, 47:823-834.

Barlow, J.A. 1979. Preface, p. vii-xviii. In Barlow J.A. (ed.), Proceedings of the First I. C. White Memorial Symposium "The Age of the Dunkard." West Virginia Geological and Economic Survey, Morgantown.

Barrick, J.E., Lambert, L.L., Heckel, P.H., and Boardman, D.R. 2004. Pennsylvanian conodont zonation for midcontinent North America. Revista Española de Micropaleontologia, 36:231250.

Benson, R.B.J. 2012. Interrelationships of basal synapsids: Cranial and postcranial morphological partitions suggest different topologies. Journal of Systematic Palaeontology, 10:601-624. https://doi.org/10.1080/14772019.2011.631042

Berman, D.S. 1979. Edaphosaurus (Reptilia, Pelycosauria) from the lower Permian of northeastern United States, with description of a new species. Annals of the Carnegie Museum, 48:185-202.

Berman, D.S. and Reisz, R.R. 1982. Restudy of Mycterosaurus longiceps (Reptilia, Pelycosauria) from the lower Permian of Texas. Annals of the Carnegie Museum, 52:423453.

Berman, D.S., Henrici, A.C., and Lucas, S.G. 2015. Pennsylvanian-Permian red bed vertebrate localities of New Mexico and their assemblages. New Mexico Museum of Natural History and Science Bulletin, 68:65-76.

Berman, D.S., Sumida, S.S., and Lombard, R.E. 1997. Biogeography of primitive amniotes, p. 85-139. In Sumida, S.S. and Martin, K.L.M. (eds.), Amniote Origins: Completing the Transition to Land. Academic Press, San Diego. https://doi.org/10.1016/b978-012676460-4/ 50005-6

Bramble, D.M. and Wake, D.B. 1985. Feeding mechanisms of lower tetrapods, p. 230-261. In Hildebrand, M., Bramble, D.W., Liem, K.F., and Wake, D.B. (eds.), Functional Vertebrate 
Morphology. Harvard University Press, Cambridge. https://doi.org/10.4159/ harvard.9780674184404.c13

Brocklehurst, N., Kammerer, C.F., and Fröbisch, J. 2013. The early evolution of synapsids and the influence of sampling on their fossil record. Paleobiology, 39:470-490. https://doi.org/ $10.1666 / 12049$

Case, E.C. 1906a. Revision of the Pelycosauria of North America. The Carnegie Institution of Washington Publication, 55:1-176. https://doi.org/10.5962/bhl.title.45536

Case, E.C. 1906b. On the skull of Edaphosaurus pogonias Cope. Bulletin of the American Museum of Natural History, 22:19-26.

Case, E.C. 1908. Description of vertebrate fossils from the vicinity of Pittsburgh, Pennsylvania. Annals of the Carnegie Museum, 4:234-241.

Case, E.C. 1918. A mounted skeleton of Edpahosaurus cruciger Cope, in the geological collection of the University of Michigan. Occasional Papers of the Museum of Zoology University of Michigan, 62:1-13.

Cooper, W.E., Jr. and Vitt, L.J. 2002. Distribution, extent, and evolution of plant consumption by lizards. Journal of Zoology London, 257:487-517. https://doi.org/10.1017/ s0952836902001085

Cope, E.D. 1882. Third contribution to the history of the Vertebrata of the Permian formation of Texas. Proceedings of the American Philosophical Society, 20: 447-461.

Davydov, V.I., Glenister, B.F., Spinosa, C., Ritter, S.M., Chernykh, V.V., Wardlaw, B.R., and Snyder, W.S. 1998. Proposal of Aidaralash as Global Stratotype Section and Point (GSSP) for base of the Permian System. Episodes, 21:11-17.

DiMichele, W.A., Chaney, D.S., Kerp, H., and Lucas, S.G. 2010. Late Pennsylvanian floras in western equatorial Pangea, Cañon del Cobre, New Mexico. New Mexico Museum of Natural History and Science Bulletin, 49:75-133.

DiMichele, W.A., Eble, C.F., and Chaney, D.S. 1996. A drowned lycopsid forest above the Mahoning coal (Conemaugh Group, Upper Pennsylvanian) in eastern Ohio, U.S.A. International Journal of Coal Geology, 31:249-276. https://doi.org/10.1016/s01665162(96)00019-5

Dodson, P. 1975. Functional and ecological significance of relative growth in Alligator. Journal of Zoology London, 175:315-355. https://doi.org/10.1111/j.1469-7998.1975.tb01405.x

Edmunds, W.E., Skema, V.W., and Flint, N.K. 1999. Pennsylvanian, p. 149-169. In Shultz, C.H. (ed.), The Geology of Pennsylvania. Pennsylvania Geological Survey, Harrisburg.

Elbroch, M. 2006. Animal Skulls: A Guide to North American Species. Stackpole Books, Mechanicsburg, PA.

Farag, F.M., Daghash, S.M., Mohamed, E.F., Hussein, M.M., and Hagrass, S.M. 2012. Anatomical studies on the skull of the domestic rabbit (Oryctolagus cuniculus) with special reference to the hyoid apparatus. Journal of Veterinary Anatomy, 5:49-70.

Fritsch, A. 1895. Über neue Wirbeltiere aus der Permianformation Böhmens, nebst einer Übersicht der aus derselben bekannt gewordenen Arten. Sitzungsberichte Koningliche Böhmische Gesellschaft der Wissenschaften, 53:1-17.

Fröbisch, J., Schoch, R.R., Müller, J., Schindler, T., and Schweiss, D. 2011. A new basal sphenacodontid synapsid from the Late Carboniferous of the Saar-Nahe basin, Germany. Acta Palaeontologia Polonica, 56:113-120. https://doi.org/10.4202/app.2010.0039

Galton, P. 1973. The cheeks of ornithischian dinosaurs. Lethaia, 6:67-89. https://doi.org/10.1111/ j.1502-3931.1973.tb00873.x

Gilbert, B.M. 1990. Mammalian Osteology. Missouri Archaeological Society, Columbia.

Gould, S.J. 1970. Evolutionary paleontology and the science of form. Earth Sciences Review, 6:77-119. https://doi.org/10.1016/0012-8252(70)90027-9

Harris, S.K., Lucas, S.G., Berman, D.S., and Henrici, A.C. 2004. Vertebrate fossil assemblage from the Upper Pennsylvanian Red Tanks Member of the Bursum Formation, Lucero uplift, central New Mexico. New Mexico Museum of Natural History and Science Bulletin, 25:267283.

Hayek, L.-A.C. and Buzas, M.A. 1997. Surveying Natural Populations. Columbia University Press, New York.

Heckel, P.H., Barrick, J.E., and Rosscoe, S.J. 2011. Conodont-based correlation of marine units in lower Conemaugh Group (Late Pennsylvanian) in northern Appalachian basin. Stratigraphy, 8:253-269. 
Heckel, P.H., Alekseev, A.S., Barrick, J.E., Boardman, D.R., Goreva, N.V., Nemyrovska, T.I., Ueno, K., Villa, E., and Work, D.M. 2007. Cyclothem ("digital") correlation and biostratigraphy across the global Moscovian-Kasimovian-Gzhelian stage boundary interval (Middle-Upper Pennsylvanian) in North America and eastern Europe. Geology, 35:607-610. https://doi.org/ 10.1130/g23564a.1

Hentz, T.F. 1988. Lithostratigraphy and paleoenvironments of Upper Paleozoic continental red beds, north-central Texas: Bowie (new) and Wichita (revised) Groups. The University of Texas at Austin, Bureau of Economic Geology, Report of Investigations, 170:1-55. https:// doi.org/10.23867/ri0170d

Herring, S.W. and Herring, S.E. 1974. The superficial masseter and gape in mammals. The American Naturalist, 108: 561-576. https://doi.org/10.1086/282934

Hiiemae, K.M. 1967. Masticatory function in mammals. Journal of Dental Research, 46:883-893. https://doi.org/10.1177/00220345670460054601

Hiiemae, K.M. and Ardran, G.M. 1968. A cinefluorographic study of mandibular movement during feeding in the rat (Rattus norvegicus). Journal of Zoology, London, 154:139-154. https:// doi.org/10.1111/j.1469-7998.1968.tb01654.x

Hiiemae, K.M. and Houston, W.J.B. 1971. The structure and function of the jaw muscles in the rat (Rattus norvegicus L.) I. Their anatomy and internal architecture. Zoological Journal of the Linnaean Society, 50:75-99. https://doi.org/10.1111/j.1096-3642.1971.tb00752.x

Hildebrand, M. and Goslow, G.E. 2001. Analysis of Vertebrate Structure. 5th Edition. John Wiley and Sons, New York.

Honey, J.G., Harrison, J.A., Prothero, D.R., and Stevens, M.S. 1998. Camelidae, p. 439-462. In Janis, C., Scott, K.M., and Jacobs, L.L. (eds.), Evolution of Tertiary Mammals of North America, Volume 1: Terrestrial Carnivores, Ungulates, and Ungulate-like Mammals. Cambridge University Press, Cambridge.

Hook, R.W. 1989. Stratigraphic distribution of tetrapods in the Bowie and Wichita groups, PermoCarboniferous of north-central Texas, p. 47-53. In Hook, R.W. (ed.), Permo-Carboniferous Vertebrate Paleontology, Lithostratigraphy, and Depositional Environments of North-central Texas. Field Trip Guidebook 2. Society of Vertebrate Paleontology, 49th Annual Meeting, Austin, Texas.

Horner, J.R., Weishampel, D.B., and Forster, C.A. 2004. Hadrosauridae, p. 438-463. In Weishampel, D.B., Dodson, P., and Osmólska, H. (eds.), The Dinosauria. Second Edition. University of California Press, Berkeley. https://doi.org/10.1525/california/ 9780520242098.003.0023

Hotton, N., III. 1955. A survey of adaptive relationships of dentition and diet in the North American Iguanidae. American Midland Naturalist, 53:88-114. https://doi.org/10.2307/ 2422301

Hotton, N., III, Olson, E.C., and Beerbower, R. 1997. Amniote origins and the discovery of herbivory, p. 207-264. In Sumida, S.S. and Martin, K.L.M. (eds.), Amniote Origins: Completing the Transition to Land. Academic Press, San Diego. https://doi.org/10.1016/ b978-012676460-4/50008-1

Hurlburt, G. 1999. Comparison of body mass estimation techniques, using Recent reptiles and the pelycosaur Edaphosaurus boanerges. Journal of Vertebrate Paleontology, 19:338-350. https://doi.org/10.1080/02724634.1999.10011145

Iverson, J.B. 1982. Adaptations to herbivory in iguanine lizards, p. 60-76. In Burghardt, G.M. and Rand, A.S. (eds.), Iguanas of the World. Noyes, Park Ridge.

Jaekel, O. 1910. Naosaurus credneri im Rotliegenden von Sachsen. Zeitschrift Deutsche Geologische Gesellschaft, 62:526-535.

Janis, C.M. and Ehrhardt, D. 1988. Correlation of relative muzzle width and relative incisor width with dietary preference in ungulates. Zoological Journal of the Linnaean Society, 92:267-284. https://doi.org/10.1111/j.1096-3642.1988.tb01513.x

Johnson, L.J. 2008. Mountain Goat. Alaska Department of Fish and Game Educational Material, Revised and Reprinted by K. White. Alaska Department of Fish and Game, Juneau, Alaska, USA. https://www.adfg.alaska.gov/static/education/wns/mountain_goat.pdf

Kemp, T.S. 1982. Mammal-like Reptiles and the Origin of Mammals. Academic Press, New York. Kemp, T.S. 2005. The Origin and Evolution of Mammals. Oxford University Press, Oxford.

King, G. 1996. Reptiles and Herbivory. Chapman and Hall, London.

Krainer, K. and Lucas, S.G. 2013. The Pennsylvanian-Permian Bursum Formation in central New Mexico. New Mexico Museum of Natural History and Science Bulletin, 59:143-160. 
Krainer, K., Vachard, D., and Lucas, S.G. 2003. Microfacies and microfossil assemblages (smaller foraminifers, algae, pseudoalgae) of the Hueco Group and Laborcita Formation (Upper Pennsylvanian-lower Permian), south-central New Mexico, USA. Rivista Italiana di Paleontologia e Stratigrafia, 109:3-36.

Kubota, K. and Kobayashi, Y. 2009. Evolution of dentary diastema in iguanodontian dinosaurs. Acta Geologica Sinica, 83:39-45. https://doi.org/10.1111/j.1755-6724.2009.00005.x

Laurin, M. 1993. Anatomy and relationships of Haptodus garnettensis, a Pennsylvanian synapsid from Kansas. Journal of Vertebrate Paleontology, 13:200-229. https://doi.org/ 10.1080/02724634.1993.10011501

Lieberman, D.E. and Crompton, A.W. 2000. Why fuse the mandibular symphysis? A comparative analysis, American Journal of Physical Anthropology, 112:517-540. https://doi.org/10.1002/ 1096-8644(200008)112:4<517::aid-ajpa7>3.3.co;2-w

Lucas, S.G. 2006. Global Permian tetrapod biostratigraphy and biochronology, p. 65-93. In Lucas, S.G., Cassinis, G., and Schneider, J.W. (eds.), Non-marine Permian Biostratigraphy and Biochronology. Geological Society, London, Special Publications, 265. The Geological Society, London. https://doi.org/10.1144/gsl.sp.2006.265.01.04

Lucas, S.G. 2013a. Vertebrate biostratigraphy and biochronology of the upper Paleozoic Dunkard Group, Pennsylvanian-West Virginia-Ohio, USA. International Journal of Coal Geology, 119:79-87. https://doi.org/10.1016/j.coal.2013.04.007

Lucas, S.G. 2013b. We need a new GSSP for the base of the Permian: Permophiles, 58:8-12.

Lucas, S.G. 2017. Permian tetrapod extinction events. Earth-Science Reviews, 170:31-60. https://doi.org/10.1016/j.earscirev.2017.04.008

Lucas, S.G. 2018. Permian tetrapod biochronology, correlation and evolutionary events, p.405444. In Lucas, S.G. and Shen, S.Z. (eds.), The Permian Timescale, Geological Society, London, Special Publications 450. The Geological Society, London. https://doi.org/10.1144/ sp450.12

Lucas, S.G., Harris, S.K., Spielmann, J.A., Berman, D.S., Henrici, A.C., Heckert, A.B., Zeigler, K.E., and Rinehart, L.F. 2005. Early Permian vertebrate assemblage and its biostratigraphic significance, Arroyo del Agua, Rio Arriba County, New Mexico, p. 288-296. In Lucas, S.G., Zeigler, K.E., Lueth, V.W., and Owen, D.E. (eds.), Geology of the Chama Basin. New Mexico Geological Society 56th Fall Field Conference Guidebook. New Mexico Geological Society, Socorro.

Lucas, S.G., Harris, S.K., Spielmann, J.A., Rinehart, L.F., Berman, D.S., Henrici, A.C., and Krainer, K. 2010. Vertebrate paleontology, biostratigraphy and biochronology of the Pennsylvanian-Permian Cutler Group, Cañon del Cobre, northern New Mexico. New Mexico Museum of Natural History and Science Bulletin, 49:115-123.

Lucas, S.G., Kollar, A.D., Berman, D.S., and Henrici, A.C. 2016. Pelycosaurian-grade (Amniota: Synapsida) footprints from the lower Permian Dunkard Group of Pennsylvania and West Virginia. Annals of Carnegie Museum, 83:287-294. https://doi.org/10.2992/007.083.0404

Lucas, S.G., Krainer, K., Voigt, S., Berman, D.S., and Henrici, A. 2014. The lower Permian Abo Formation in the northern Sacramento Mountains, southern New Mexico, p. 287-302. In Rawling, G., McLemore, V.T., Timmons, S., and Dunbar, N. (eds.), Geology of the Sacramento Mountains Region. New Mexico Geological Society, 65 ${ }^{\text {th }}$ Fall Field Conference Guidebook. New Mexico Geological Society, Socorro.

Lucas, S.G., Rowland, J.M., Kues, B.S., Estep, J.W., and Wilde, G.L. 1999. Uppermost Pennsylvanian and Permian stratigraphy and biostratigraphy at Placitas, New Mexico, p. 281-292. In Pazzaglia, F.J., Lucas, S.G., and Austin, G.S. (eds.), Albuquerque Geology. New Mexico Geological Society, 50th Fall Field Conference Guidebook. New Mexico Geological Society, Socorro.

Lund, R., Gaston, E.R., and Weishampel, D.B. 1979. Fossil vertebrates of the Pennsylvanian System of West Virginia, p.105-107. In Englund, K.J., Arndt, H.H., and Henry, T.W. (eds.), Proposed Pennsylvanian System Stratotype Virginia and West Virginia. $9^{\text {th }}$ International Congress of Carboniferous Stratigraphy and Geology, Fieldtrip Guidebook No. 1. American Geosciences Institute, Alexandria.

Maddison, W.P. and Maddison, D.R. 2017. Mesquite: a modular system for evolutionary analysis. Version 3.2. http://mesquiteproject.org.

Marks, L.S. 1951. Mechanical Engineers' Handbook. McGraw-Hill Book Co., New York. 
Mazierski, D.M. and Reisz, R.R. 2010. Description of a new specimen of lanthasaurus hardestiorum (Eupelycosauria: Edaphosauridae) and a re-evaluation of edaphosaurid phylogeny. Canadian Journal of Earth Sciences, 47:901-912. https://doi.org/10.1139/e10-017

Modesto, S.P. 1994. The lower Permian synapsid Glaucosaurus from Texas. Palaeontology, 37:51-60.

Modesto, S.P. 1995. The skull of the herbivorous synapsid Edaphosaurus boanerges from the lower Permian of Texas. Palaeontology, 38:213-239.

Modesto, S.P. and Reisz, R.R. 1990a. Taxonomic status of Edaphosaurus raymondi Case. Journal of Paleontology, 64:1049-1051. https://doi.org/10.1017/s0022336000019910

Modesto, S.P. and Reisz, R.R. 1990b. A new skeleton of lanthasaurus hardesii, a primitive edaphosaur (Synapsida: Pelycosauria) from the Upper Pennsylvanian of Kansas. Canadian Journal of Earth Sciences, 27:834-844. https://doi.org/10.1139/e90-086

Modesto, S.P. and Reisz, R.R. 1992. Restudy of Permo-Carboniferous synapsid Edaphosaurus novomexicanus Williston and Case, the oldest known herbivorous amniote. Canadian Journal of Earth Sciences, 29:2653-2662. https://doi.org/10.1139/e92-210

Modesto, S.P., Scott, D.M., MacDougall, M.J., Sues, H.-D., Evans, D.C., and Reisz, R.R. 2015. The oldest parareptile and the early diversification of reptiles. Proceedings of the Royal Society B, 282:20141912. https://doi.org/10.1098/rspb.2014.1912

Montanucci, R.R. 1968. Comparative dentition in four iguanid lizards. Herpetologica, 24:305315.

Morhardt, A.C. 2009. Dinosaur smiles: Do the texture and morphology of premaxilla, maxilla, and dentary bones of sauropsids provide osteological correlates for inferring extra-oral structures reliably in dinosaurs? MS thesis, Western Illinois University, Macomb, Illinois, USA.

Norman, D.B. and Weishampel, D.B. 1985. Ornithopod feeding mechanisms: Their bearing on evolution of herbivory. The American Naturalist, 126:151-164. https://doi.org/10.1086/284406

Ogg, J.G., Ogg, G.M., and Gradstein, F.M. 2016. A Concise Geologic Time Scale. Elsevier, Amsterdam.

Olson, E.C. 1989. The Arroyo Formation (Leonardian: lower Permian) and its vertebrate fauna. Texas Memorial Museum Bulletin, 2:1-25.

Olson, E.C. and Mead, J.G. 1982. The Vale Formation (Lower Permian) its vertebrates and paleoecology. Texas Memorial Museum Bulletin, 29:1-46.

Opluštil, S., Schmitz, M., Cleal, C.J., and Martinek, K. 2016. A review of the Middle-Late Pennsylvanian west European regional substages and floral biozones, and their correlation to the geological time scale based on new U-Pb ages. Earth-Science Reviews, 154:301-335. https://doi.org/10.1016/j.earscirev.2016.01.004

Osborn, H.F. 1903. On the primary division of the Reptilia into two subclasses, Synapsida and Diapsida. Science, 17:275-276. https://doi.org/10.1126/science.17.424.275-b

Otte, C., Jr. 1959. Late Pennsylvanian and early Permian stratigraphy of the northern Sacramento Mountains, Otero County, New Mexico. New Mexico Bureau of Mines and Mineral Resources Bulletin, 50:1-111.

Peabody, F.E. 1957. Pennsylvanian reptiles of Garnett, Kansas: Edaphosaurus. Journal of Paleontology, 31:947-949.

Pérez-Barbería, E.J. and Gordon, I.J. 1999. The functional relationship between feeding type and jaw and cranial morphology in ungulates. Oecologia, 118:157-165. https://doi.org/ $10.1007 / \mathrm{s} 004420050714$

Peyer, B. 1968. Comparative Odontology. The University of Chicago Press, Chicago.

Popowics, T.E. and Herring, S.W. 2006. Teeth, jaws and muscles in mammalian mastication, p. 61-83. In Bels, V. (ed.), Feeding in Domestic Vertebrates: From Structure to Behaviour. CAB International, Wallingford. https://doi.org/10.1079/9781845930639.0061

Porter, W.R. and Witmer, L.M. 2015. Vascular patterns in iguanas and other squamates: Blood vessels and sites of thermal exchange. PLOS ONE, 10(10):e0139215. https://doi.org/ 10.1371/journal.pone.0139215

Pray, L.C. 1961. Geology of the Sacramento Mountains escarpment, Otero County, New Mexico. New Mexico Bureau of Mines and Mineral Resources Bulletin, 35:1-143.

Prothero, D.R. and Foss, S.E., eds. 2007. The Evolution of Artiodactyls. Johns Hopkins University Press, Baltimore.

Ramezani, J. and Bowring, S.A. 2018. Advances in numerical calibration of the Permian timescale based on radioisotopic geochronology, p. 51-60. In Lucas, S.G. and Shen, S.Z. 
(eds.), The Permian Timescale. Geological Society, London, Special Publications 450. The Geological Society, London. https://doi.org/10.1144/sp450.17

Reisz, R.R. 1986. Pelycosauria, Encyclopedia of Paleoherpetology, 17A. Gustav Fischer Verlag, Stuttgart.

Reisz, R.R. and Berman, D. S. 1986. lanthasaurus hardestii n. sp., a primitive edaphosaur (Reptilia, Pelycosauria) from the Upper Pennsylvanian Rock Lake Shale near Garnett, Kansas. Canadian Journal of Earth Sciences, 23:77-91. https://doi.org/10.1139/e86-008

Reisz, R.R. and Fröbisch, J. 2014. The oldest caseid synapsid from the Late Pennsylvanian of Kansas, and the evolution of herbivory in terrestrial vertebrates. PLOS ONE, 9(4):e94518. https://doi.org/10.1371/journal.pone.0094518

Reisz, R.R., Heaton, M.J. and Pynn, B.R. 1982. Vertebrate fauna of Late Pennsylvanian Rock Lake Shale near Garnett, Kansas: Pelycosauria. Journal of Paleontology, 56:741-750.

Reisz, R.R. and Sues, H.-D. 2000. Herbivory in late Paleozoic and Triassic terrestrial vertebrates, p. 9-41. In Sues, H.-D. (ed.), Evolution of Herbivory in Terrestrial Vertebrates. Cambridge University Press, Cambridge. https://doi.org/10.1017/cbo9780511549717.003

Rinehart, L.F. and Lucas, S.G. 2013. Tooth form and function in temnospondyl amphibians: Relationship of shape to applied stress. New Mexico Museum of Natural History and Science Bulletin, 61:533-542.

Rinehart, L.F., Lucas, S.G., Tanner, L., Nelson, W.J., Elrick, S.D., Chaney, D.S., and DiMichele, W.A. 2015. Plant architecture and spatial structure of an early Permian woodland buried by flood waters, Sangre de Cristo Formation, New Mexico. Palaeogeography, Palaeoclimatology, Palaeoecology,424:91-110. https://doi.org/10.1016/j.palaeo.2015.02.018

Romer, A.S. 1937. New genera and species of pelycosaurian reptiles. Proceedings of the New England Zoological Club, 16:89-96.

Romer, A.S. 1952. Late Pennsylvanian and early Permian vertebrates of the Pittsburgh-West Virginia region. Annals of the Carnegie Museum, 33:47-113.

Romer, A.S. 1956. Osteology of the Reptiles. University of Chicago Press, Chicago.

Romer, A.S. and Price, L.W. 1940. Review of the Pelycosauria, Geological Society of America Special Papers, 27:1-486. https://doi.org/10.1130/spe28-p1

Roscher, M. and Schneider, J.W. 2006. Permo-Carboniferous climate: Early Pennsylvanian to late Permian climate development of central Europe in a regional and global context, p. 95136. In Lucas, S.G., Cassinis, G., and Schneider, J.W. (eds.), Non-marine Permian Biostratigraphy and Biochronology. Geological Society, London, Special Publications, 265. The Geological Society, London. https://doi.org/10.1144/gsl.sp.2006.265.01.05

Schmitz, M.D. and Davydov, V.I. 2012. Quantitative radiometric and biostratigraphic calibration of the Pennsylvanian-early Permian (Cisuralian) time scale and pan-Euramerican chronostratigraphic correlation. Geological Society of America Bulletin, 124:549-577. https:// doi.org/10.1130/b30385.1

Schneider, J.W. and Werneburg, R. 2012. Biostratigraphie des Rotliegend mit Inseketen un Amphibien. Schriftenreihe der Deutschen Gesellschaft für Geowissenschaften, 61:110-142.

Schneider, J.W., Lucas, S.G., and Barrick, J.E. 2013. The early Permian age of the Dunkard Group, Appalachian basin, U.S.A., based on spilobattinid insect biostratigraphy. International Journal of Coal Geology, 199:88-92. https://doi.org/10.1016/j.coal.2013.07.019

Schwartz, G., Enomoto, S., Valiquette, C., and Lund, J.P. 1989. Mastication in the rabbit: A description of movement and muscle activity: Journal of Neurophysiology, 62:273-287. https:/ /doi.org/10.1152/jn.1989.62.1.273

Smith, K. 1993. The form of the feeding apparatus in terrestrial vertebrates: Studies of adaptation and constraint, p. 150-196. In Hanken, J. and Hall, B.K. (eds.), The Skull, Volume 3: Functional and Evolutionary Mechanisms. University of Chicago Press, Chicago.

Smith, R., Rubidge, B., and van der Walt, M. 2012. Therapsid biodiversity patterns and paleoenvironments of the Karoo basin, South Africa, p. 31-62. In Chinsamy-Turan, A. (ed.), Forerunners of Mammals. Indiana University Press, Bloomington and Indianapolis.

Spindler, F. 2015. The Basal Sphenacodontia-Systematic Revision and Evolutionary Implications. Ph.D. thesis, Freiberg Technische Universität Bergakademie, Freiberg, Germany.

Spindler, F., Falconnet, J., and Fröbisch, J. 2016. Callibrachion and Datheosaurus, two historical and previously mistaken basal caseasaurian synapsids from Europe. Acta Palaeontologica Polonica, 61:597-616. https://doi.org/10.4202/app.00221.2015 
Štamberg, S. and Zajíc, J. 2008. Carboniferous and Permian Faunas and Their Occurrence in the Limnic Basins of the Czech Republic. Museum of Eastern Bohemia, Hradec Králové.

Steiner, M.B. and Williams, T.E. 1968. Fusulinidae of the Laborcita Formation (lower Permian), Sacramento Mountains, New Mexico. Journal of Paleontology, 42:51-60.

Sues, H.-D. 1986. The skull and dentition of two tritylodontid synapsids from the Lower Jurassic of western North America. Bulletin of the Museum of Comparative Zoology, Harvard University, 151:217-268.

Sues, H.-D. and Reisz, R.R. 1998. Origins and early evolution of herbivory in tetrapods. Trends in Ecology \& Evolution, 13:141-145. https://doi.org/10.1016/s0169-5347(97)01257-3

Sumida, S.S. 1989. New information on the pectoral girdle and vertebral column in Lupeosaurus (Reptilia, Pelycosauria). Canadian Journal of Earth Sciences, 26:1343-1349. https://doi.org/ 10.1139/e89-113

Sumida, S.S. 1990. Vertebral morphology, alternation of neural spine height, and structure in Permo-Carboniferous tetrapods, and a reappraisal of primitive modes of terrestrial locomotion. University of California Publications in Zoology, 122:1-129.

Sumida, S.S. and Berman, D.S. 1993. The pelycosaurian (Amniota: Synapsida) assemblage from the Late Pennsylvanian Sangre de Cristo Formation of central Colorado. Annals of Carnegie Museum, 62:293-310.

Swofford, D.L. 2002. PAUP* Phylogenetic Analysis Using Parsimony ("and Other Methods). Version 4. Sinauer Associates, Sunderland, Massachusetts.

Thompson, M.L. 1942. Pennsylvanian System in New Mexico. New Mexico Bureau of Mines and Mineral Resources Bulletin, 17:1-92.

Tibert, N.E., Rygel, M.C., Sanders, S.C., Elrick, S.D., and Nelson, J. 2013. Temporal and spatial distribution of ostracodes across the Pennsylvanian-Permian boundary interval in eastern North America. International Journal of Coal Geology, 199:93-105. https://doi.org/10.1016/ j.coal.2013.08.002

Troyer, K. 1984. Diet selection and digestion in Iguana iguana: The importance of age and nutrient requirements. Oecologia, 61:201-207. https://doi.org/10.1007/bf00396761

Utting, J. and Lucas, S.G. 2010. Palynological investigation of the Upper Pennsylvanian (Carboniferous) El Cobre Canyon Formation, Cutler Group, Canon del Cobre, Rio Arriba County, New Mexico, U.S.A. New Mexico Museum of Natural History and Science Bulletin, 49:71-73.

Vachard, D., Krainer, K., and Lucas, S.G. 2015. Late early Permian (late Leonardian: Kungurian) algae, microproblematica, and smaller foraminifera from the Yeso Group and San Andres Formation (New Mexico; USA). Palaeontologia Electronica, 18.1.21A. https://doi.org/ $10.26879 / 433$ palaeo-electronica.org/content/2015/1160-kungurian-of-new-mexico

Vaughn, P.P. 1963. The age and the locality of the Paleozoic vertebrates from El Cobre Canyon, Rio Arriba County, New Mexico. Journal of Paleontology, 37:283-296.

Vaughn, P.P. 1969a. Upper Pennsylvanian vertebrates from the Sangre de Cristo Formation of central Colorado. Los Angeles County Museum of Natural History Contributions in Science, 164:1-28.

Vaughn, P.P. 1969b. Early Permian vertebrates from southern New Mexico and their paleozoogeographic significance. Los Angeles County Museum Contributions in Science, 166:1-22.

Vaughn, P.P. 1972. More vertebrates, including new microsaur, from the Upper Pennsylvanian of central Colorado. Los Angeles County Museum of Natural History Contributions in Science, 223:1-30.

Vermeij, G.J. 1999. A serious matter with character-taxon matrices. Paleobiology, 25:431-433. https://doi.org/10.1017/s0094837300020297

Voigt, S. 2005. Die Tetrapodenichnofauna des Kontinentalen Oberkarbon und Perm im Thuringer Wald-Ichnotaxonomie, Paläoökologie und Biostratigraphie. Cuvillier Verlag, Göttingen.

Voigt, S., Fischer, J., Schindler, T., Wuttke, M., Spindler, F., and Rinehart, L. 2014. On a potential fossil hotspot for Pennsylvanian-Permian non-aquatic vertebrates in central Europe. Freiberger Forschungshefte, C548:39-44.

Voigt, S. and Ganzelewski, M. 2010. Toward the origin of amniotes: Diadectomorph and synapsid footprints from the early Late Carboniferous of Germany. Acta Palaeontologica Polonica, 55:57-72. https://doi.org/10.4202/app.2009.0021 
Voigt, S. and Lucas, S.G. 2018. Outline of a Permian tetrapod footprint ichnostratigraphy, p. 387404. In Lucas, S.G. and Shen, S.Z. (eds.), The Permian Timescale. The Geological Society, London, Special Publications 450. The Geological Society, London. https://doi.org/10.1144/ $\mathrm{sp} 450.10$

Wardlaw, B.R. 2005. Age assignment of the Pennsylvanian-early Permian succession of north central Texas. Permophiles, 46:21-22.

Williston, S.W. 1915. New genera of Permian reptiles. American Journal of Science, 39:575-579. https://doi.org/10.2475/ajs.s4-39.233.575

Williston, S.W. and Case, E.C. 1913. A description of Edaphosaurus Cope. Carnegie Institution of Washington Publication, 18:71-81.

Woodward, A., Moore, T.C., and Delany, M.F. 1991. Alligator research: Experimental alligator harvest, final performance report. Statewide Wildlife Research Study, 7567:1-157.

Zar, J.H. 1999. Biostatistical Analysis. Pearson Education, Delhi. 


\section{SUPPLEMENTAL MATERIAL}

Character states of edaphosaurids used to construct the phylogenetic hypotheses in Figure 15.

\section{Character states for Gordodon}

$\begin{array}{ccccccccccccccccccccccc}1 & 2 & 3 & 4 & 5 & 6 & 7 & 8 & 9 & 10 & 11 & 12 & 13 & 14 & 15 & 16 & 17 & 18 & 19 & 20 \\ 1 & 0 & 0 & 1 & 0 & 1 & 0 & 2 & 1 & 0 & 1 & 1 & 1 & 1 & 1 & 1 & 1 & 1 & ? & ? \\ & & & & & & & & & & & & & & & & & & & & & & \\ 1 & 23 & 24 & 25 & 26 & 27 & 28 & 29 & 30 & 31 & 32 & 33 & 34 & 35 & 36 & 37 & 38 & 39 \\ 1 & 1 & 0 & 1 & 0 & 1 & 2 & 1 & 1 & 0 & 1 & ? & ? & ? & ? & ? & 0 & ? & ?\end{array}$

\section{Character descriptions}

All characters taken from Mazierski and Reisz (2010), which was based on a data matrix developed by Modesto (1995). Corrections and modifications are noted below:

1. Marginal teeth: taper gradually (0) or slightly bulbous (1). The marginal teeth of Gordodon are slightly swollen near their tips (1).

2. Marginal teeth: cutting edges absent (0) or present (1) on mesial and distal surfaces. No indications of cutting edges are visible on the marginal teeth of Gordodon (0).

3. Premaxillary dentition: larger than $(0)$ or equal to or smaller than maxillary teeth (1) in basal cross section. The greatly enlarged premaxillary teeth of Gordodon are unique among basal synapsids (0).

4. Caniniform region: present (0) or absent (1). No caniniform (or indeed, any) teeth are present in the anterior maxilla of Gordodon (1).

5. Caniniform tooth: absent (0) or present (1). The states for characters 4 and 5 are confusingly described as the reverse of each other in previous edaphosaur studies. Modesto (1995) listed this character as absent (0) or present (1) but coded his matrix oppositely. Mazierski and Reisz (2010) corrected the coding for all taxa except Edaphosaurus novomexicanus, which they coded as possessing a caniniform tooth (1). Our examination of the holotype of $E$. novomexicanus found no indication of a caniniform tooth, and we have coded it as absent (0) in this study.

6. Maxilla: long, extends past orbit (0) or short, does not extend past orbit (1). The maxilla of Gordodon stops beneath the middle of the orbit (1).

7. Maxillary and dentary alveolar ridges: straight (0) or twisted (1). Although the posterior maxillary teeth of Gordodon are pushed outward slightly from being compressed against the underlying dentary, there is no indication of the twisted alveolar tooth row that is present in Edaphosaurus (0).

8. Maxillary dentition: $30-40$ tooth positions (0), 20 to 30 tooth positions (1), or less than 20 tooth positions (2). Gordodon and Edaphosaurus have a comparable number of maxillary teeth $(<20)$, although the teeth of Gordodon are proportionally smaller and limited to the posterior half of the maxilla (2).

9. Prefrontal: ventral process tongue-like (0) or expanded medially (1). The ventral process of the prefrontal extends medially into the orbit in Gordodon (1).

10. Frontal: lateral lappet broad (0) or narrow (1). In Gordodon, a broad lappet of the frontal extends laterally between the preand postfrontals to make up $\sim 25 \%$ of the dorsal margin of the orbit (0).

11. Supraorbital margin: interorbital width less than the frontal sagittal length $(0)$ or expanded laterally (1). As in Edaphosaurus, the supraorbital bones extend laterally beyond the orbit in Gordodon (1).

12. Parietal: in dorsal view, lateral margin is straight or convex (0) or concave (1). Concave in Gordodon (1). 
13. Postorbital: contacts squamosal (0) or separate from squamosal (1). The postorbital does not contact the squamosal in Gordodon (1).

14. Quadratojugal: large, forming the ventral margin of the posterior cheek (0) or small, covered laterally by the squamosal (1). The quadratojugal appears to be a small element in Gordodon (1).

15. Quadrate: separate, distinct condyles (0) or broad, saddle-shaped articular surface (1). The articular surface of the quadrate is saddle-shaped in Gordodon (1).

16. Jaw suspension: level with maxillary tooth row (0) or offset ventrally from maxillary tooth row (1). The jaw suspension in Gordodon is offset ventrally, although not as dramatically as is seen in Edaphosaurus (1).

17. *Skull: Length greater than $30 \%$ of presacral length (0) or less than $25 \%$ of presacral length (1). Mazierski and Reisz (2010) compared skull length to dorsal vertebrae for this character: eight or more dorsal centra in length $(0)$ or five or fewer dorsal centra in length (1). The skull of Gordodon measures 6-7 dorsal centra in length and we opted to use the skull length character from Benson (2012) (1).

18. ${ }^{*}$ Postorbital region: shorter than antorbital region (0), equal to antorbital region (1), longer than antorbital region (2). As in characters 17 and 22, Gordodon occupies a transitional state between the states described in Mazierski and Reisz (2010). We replaced it with the 3-state character used by Benson (2012) (1).

19. Pterygoid: transverse flange present (0) or absent (1). Obscured in Gordodon (?).

20. Pterygoid: palatal ramus $\geq 2 x$ longer than quadrate ramus $(0)$ or $<2 x$ length of quadrate ramus (1). Obscured in Gordodon (?).

21. Occluding palatal and mandibular tooth plates absent (0) or present (1). Although the palatal tooth plates are obscured in Gordodon, we infer their presence from the mandibular tooth plate visible on the left jaw (1).

22. *Mandible: dorsoventral height:length less than $.26(0)$, greater than .3 (1). As in characters 16 and 17 , this character in Gordodon is in between the two states described in Mazierski and Reisz (2010). The comparable character from Benson (2012) is used here (1).

23. Dentary: $70 \%$ or more of total jaw length (0) or $66 \%$ or less of total jaw length (1). The dentary is relatively long in Gordodon (0).

24. Splenial: lateral exposure $1 / 5$ or less of total anterior jaw height (0) or $1 / 3$ or more total anterior jaw height (1). The splenial makes up approximately $1 / 3$ of the total anterior jaw height in Gordodon (1).

25. Cervical centra: length $\geq$ mid-dorsal centra length $(0)$ or shorter than mid-dorsal centra (1). The length of the cervical centra is subequal to the length of the dorsal centra in Gordodon (0).

26. Presacral neural spines: short (0) or long (more than $5 x$ centrum height) (1). Long in Gordodon (1).

27. Presacral neural spines: centrum length: neural spine height ratio is less than $1: 5$ (0), $1: 6$ to $1: 12$ (1), or $1: 13-1: 20$ (2). Extremely long in Gordodon (2).

28. Presacral neural spines: laterally compressed in distal cross section (0) or subcircular (1). Although the neural spines in Gordodon are laterally compressed, it is unclear how much of this is due to postmortem crushing. Additionally, we interpret this character as differentiating between rod-like and blade-like neural spines, and the proportions of the neural spines of Gordodon are more rod-like (1).

29. Presacral neural spines: lateral tubercles absent (0); moderately sized (1); or large, gall-like (2). The lateral tubercles of Gordodon are among the smallest known for any edaphosaur (1).

30. Presacral neural spines: anterior spines are slender (0) or club-shaped (1). None of the neural spines of Gordodon show the club-shaped morphology seen on the anterior spines of $E$. cruciger and $E$. pogonias (0).

31. Neural arches: possess lateral excavations (0) or no excavations (1). No lateral excavations are visible on the neural arches of Gordodon (1).

32. Dorsal vertebrae: moderately developed 
transverse processes (0) or elongate transverse processes (1). The right transverse processes on the dorsal vertebrae are too heavily eroded in $\mathrm{NMMNH}$ P-70796 to determine their extent (?).

33. Sacral/caudal vertebrae: neural spine tips smooth (0) or rugose (1). Unknown in Gordodon (?).

34. Sacral/caudal vertebrae: smooth spines (0) or spines with longitudinal ridges (1). Unknown in Gordodon (?).

35. Caudal vertebrae: neural spines rectangular in lateral view (0) or wider distally (1). Unknown in Gordodon (?).

36. Caudal vertebrae: neural spines short and square (0) or long and pointed (1). Unknown in Gordodon (?).
37. Dorsal ribs: curved proximally only (0) or curved throughout their length (1). Although only the proximal portion of the anterior ribs are known for Gordodon, these are relatively straight and there is no indication of the barrel-like curvature seen in Edaphosaurus (0).

38. Dorsal ribs: flange-like tubercles (0) or low tuberosities (1). The articular facets of the right ribs have been eroded from NMMNH P-70796 and the tubercula on the left side of the body are obscured beneath the vertebrae (?).

39. Ilium: anterodorsal process smaller than posterodorsal process, convex (0) or longer, triangular (1). Unknown in Gordodon (?). 